\title{
Social Touch in Human-Robot Interaction: Robot-Initiated Touches can Induce Positive Responses without Extensive Prior Bonding
}

\author{
Christian J. A. M. Willemse ${ }^{1,2}$ (D) Jan B. F. van $\operatorname{Erp}^{1,2}$
}

Accepted: 11 October 2018 / Published online: 8 November 2018

(c) The Author(s) 2018

\begin{abstract}
Social touch interactions can, depending on the type and strength of the dyadic social relationship, elicit a plethora of physiological, emotional, and behavioral responses; both beneficial and disadvantageous. With the intention to expand the communicative capabilities of humanoid social robots, we investigated whether robot-initiated touches could elicit beneficial responses in the human user that are comparable to responses to human touch. In addition, we investigated whether having a pre-existing positive social bond with the robot modulates these responses. To this end, we conducted a $2 \times 2$ between subjects experiment $(N=67)$ in which participants either did or did not establish a bond with the robot prior to interacting with it during stressful circumstances. This interaction either did or did not comprise robot-initiated touches. We hypothesized that robotic touches would attenuate the subjective and physiological stress responses during the stressful event (H1a), enhance the perceived relation with the robot (H1b), and increase one's pro-social behavior (H1c), as contrasted with interactions without touch. Based on findings from human touch, we also expected that the effects of H1a and H1b would be more outspoken when a bond with the robot was established (H2). Our findings imply that robotic touches attenuated physiological stress responses and increased the perceived intimacy of the human-robot bond. No effects were found on pro-social behavior and all effects were independent of whether a bond was formed or not. Although no full support for our hypotheses was found, the findings suggest that robot-initiated touch can, under specific circumstances, be a valuable extension of a social robot's nonverbal communication repertoire.
\end{abstract}

Keywords Human-robot interaction · Social touch $\cdot$ Human-robot bonding $\cdot$ Stress-attenuation

\section{Introduction}

Humanoid social robots emulate a variety of humanlike social cues such as speech, gaze, and facial and gestural expressions [14,15], as well as intelligent adaptive behaviors [29]. These interactions are designed to increase the robot's social presence [83] (i.e., the impression that the robot is an actual social entity), and to interact effectively with human users. Another human social cue-social touch $[39,40,43,93]$ — has thus far received relatively little atten-

Christian J. A. M. Willemse

c.j.a.m.willemse@gmail.com

Jan B. F. van Erp

jan.vanerp@tno.nl

1 Human Media Interaction Group, University of Twente, P.O. Box 217, 7500 AE Enschede, The Netherlands

2 Perceptual and Cognitive Systems Group, TNO, P.O. Box 23, 3769 ZG Soesterberg, The Netherlands tion in human-robot interaction (HRI) [131]; even though the physical embodiment of the robot enables touch interactions [84,114]. Human social touching, such as a hug or a pat on the back, can systematically change the receiver's perceptions, thoughts, feelings, and/or behavior [57], depending on how the touch feels [57], on the perceived intentions of the sender $[26,43,57]$, and on the status of the relation between toucher and touchee $[21,23,59,122]$. The question that arises is whether a robot-initiated social touch that is applied to a human recipient can also induce responses that resemble those found for human touch, and to what extent human touch protocols apply in HRI as well $[131,135]$. Preliminary research on social touch in HRI demonstrated that some (but not all) effects known for inter-human social touch also occur when a robot touches. The possibly modulating role of the relation between toucher (robot) and touchee (human user) has however not yet been investigated. In the remainder of this article, we will first elaborate on effects of social touch in human-human communication and on the 
modulating role of the dyadic social relationship. We merely focus on advantageous effects of touch and on pleasant social bonds. Next, we will argue that robot-initiated touches can have similar beneficial outcomes for human users as human touches, but that a pre-existing (positive) social bond between user and robot likely modulates these responses (comparable to human-human social touch). These discussions form the prelude to an experiment in which we investigate the responses to robot-initiated touches that are provided during a stressful scary movie. These responses include physiological stress responses, perceptions of the bond with the robot, and pro-social behavior. To investigate whether a preexisting bond with the robot modulates the responses to robot-initiated touch, half of the participants engages in interactions (e.g., small talk and playing games) with the robot to establish a bond with it prior to the scary movie. With the research as presented here, as well as with the accompanying exploratory analyses, we do not only intend to provide insights in the question whether robot-initiated touches can elicit beneficial responses, but also in the question: under which conditions? We aim at uncovering a part of the multifaceted design space that is inherent to social touch and HRI. Eventually, this research area could inform the design of physical human-robot interactions, thereby extending the robot's social communication repertoire; in particular that of robots in their envisioned role as supportive companion [16].

\section{Related Work}

\subsection{Social Touch in Human-Human Interaction}

Social touches come in many different forms [64] and can elicit a vast range of experiences and responses on a physiological, emotional, and behavioral level. Here, we will only elaborate on the (beneficial) effects that are of direct relevance for our study: touches can attenuate stress responses, strengthen the perceived relation with the toucher, and can enhance pro-social behavior. For comprehensive reviews of social touch effects, we refer to: $[39,40,43,58,93]$. Touching is the most commonly used method to comfort someone who experiences stress or negative arousal [34]. This is demonstrated in many different contexts (e.g., prior to public speaking $[33,46]$, while being threatened with physical pain [21], while watching scary videos [18,68], and prior to surgery [133]). The effectiveness of social touch in providing comfort is reflected in several physiological responses such as decreases in cortisol (i.e., the "stress-hormone" [56]), heart rate, and blood pressure. Comforting touches do not only attenuate the physiological stress responses, but also deflect one's attention from the stressors themselves $[9,68]$. Besides stress reduction, touch is the primary modality to convey affect and intimate emotions and can increase inter- personal trust and attachment $[3,40]$. As such, touch plays an important role in establishing and maintaining social bonds [51]. Moreover, social touches can induce strong behavioral responses, such as the Midas Touch effect [27,50]. This Midas Touch consists of a subtle casual touch on the arm or shoulder that is applied by a stranger, which increases the touchee's pro-social behavior. This phenomenon is demonstrated in numerous settings. After being touched, people were for example more compliant to a request to share a cigarette [65] or to participate in a survey [47], and they spent more time on a monotonous task (i.e., scoring questionnaires) [101].

\subsection{Social Relationship Status Modulates Human-Human Social Touch}

The status of the social relationship between toucher and touchee determines to a large extent the touch protocols (e.g., the appropriateness of certain touches) [122], the meanings associated with touches [119], and their effectiveness [40]. A more intimate relationship results in a better understanding of the intentions of affective touches [125], and the mere fact that two people are willing to affectively touch each other suggests an already existing sense of mutual trust and understanding [23]. The amount of body locations that are considered appropriate to be touched depends on the strength of the dyad's relation [122]. A touch from a stranger may for instance be tolerated at certain body parts such as the hands, back, or arms, but will generally be disliked [59]. Contrary to strangers, people in an intimate relationship usually touch each other relatively often and over the entire body. Physical affection is also highly correlated with (romantic) partner and relationship satisfaction [40]. The modulating effects of the strength of the relationship on responses to social touch are also reflected in the touches' stress-attenuating effects, as these are mainly found in romantic dyads $[33,46]$ or between people with a professional yet intimate relationship (e.g., nurse and patient [133]). Coan and his colleagues demonstrated that being touched, regardless by whom, effectively attenuated threat-related neural responses in women, when they were threatened with electric shocks. This attenuation was however stronger when the participant's hand was held by her spouse, than by a male stranger, and became particularly apparent for women with a higher perceived marital quality [21]. In addition, Master and colleagues demonstrate that holding the partner's hand, as contrasted with a stranger's hand or no hand, enhanced pain thresholds [92]. Interestingly, a pre-existing bond between toucher and touchee does not seem to be a prerequisite for the Midas Touch effect, as casual touches applied by strangers enhance the pro-social behavior $[27,47,49,65,101]$. Social touches thus can have a plethora of physiological, emotional, and behavioral effects, but these are to a large extent modulated by the dyadic relationship. 


\subsection{Social Touch and the Modulating Effect of Bonding in Human-Robot Interaction}

Since touch is hardly considered yet in HRI, there is no coherent understanding of whether a robot-initiated touch can have effects that are similar to those found in human touch $[131,135]$. A valuable starting point for the rationale as to why a robot-initiated touch should be able to elicit responses in the human user, is to consider the robot as a haptic interface that can emulate a human touch by means of its embodiment and internal haptic actuators. It is nearly impossible to physically emulate a human touch accurately with haptic technologies [43], but research on non-robotic haptic interfaces such as mediated social touch devices $[53,61,131]$ or other affective haptics [129] suggests that even highly degraded representations of human touch can already elicit beneficial responses. Affective haptic messages can for instance be interpreted successfully [6,119], mediated social touches can increase helping behavior [52,54], and an "Affective Tele-Touch" can decrease physiological stress responses with the same magnitude as actual human touch [18]. Since social robots employ similar haptic technologies, it is suggested that robot-initiated touches should be able to induce similar effects as humaninitiated touches [130,131,135]. Preliminary research indeed suggests that when people receive a touch from a robot, the perceived levels of trust and friendship with the robot increase $[42,60,95,98,118]$. Moreover, a touch made people more willing to carry out a monotonous task $[95,118]$ and unfair monetary offers that were proposed by the robot were perceived as less unfair after being touched [42]; examples of a Robotic Midas Touch effect. Conversely, supposedly comforting touches that accompanied soothing words from a robot did not attenuate physiological stress responses while watching a scary movie, strengthen the bond with the robot, increase the perceptions of its humanlikeness, or increase one's pro-social behavior [135]. Moreover, touches from a "nursing robot" that were intended to be comforting, were considered as less acceptable than touches that were presented as functional (i.e., cleaning the arm of the participant); even though both types of touch were physically the same [19]. These mixed findings suggest that robot-initiated touches may induce responses that are similar to responses to human touch, but only within specific boundary conditions. Considering robots merely as haptic interfaces may thus be an oversimplified approach; there is more to social touch than merely perceiving the physical qualities of a touch. The suggestion that robot-initiated touch is a multi-dimensional challenge is further supported by the findings that the perceived intentions of the touching robot [19] or the interplay between touch and other social cues such as facial expressions [128] play a significant role in touch perception.

Since there are multiple dimensions that modulate responses to robot-initiated touch, a more nuanced and more appropriate starting point for understanding the opportunities of social touch in HRI may be the Computers Are Social Actors (CASA) paradigm. CASA poses that people apply the social rules of human-human interaction, oftentimes mindlessly, when they interact with computers that exhibit anthropomorphic and/or social cues [97,106]. People for instance responded more socially and affectionately when a computer voice resembled a personality similar to their own [85], or when they were in a team with the computer [96]. Moreover, people revealed more intimate information about themselves when a computer disclosed personal information about itself first; reciprocal self-disclosure [94]. Since social robots are per definition computers that display social behavior, the CASA paradigm also applies in HRI $[72,76]$. Approaching physical HRI from the CASA perspective would thus consider robots as actual social entities, rather than as mere touching interfaces (i.e., the earlier described "Robots As Haptic Interfaces"-approach). This would also mean that mere physical stimulation from a robot does not suffice in eliciting social responses in the human user, but that additional social touching rules-such as having a pre-existing social bond-may apply. In sum, adhering to the CASA approach would thus mean that robotinitiated touches can induce similar physiological, emotional, and behavioral responses as human touches, but that these effects-like human touches-will be modulated by the type and strength of the social relationship the user has with the robot. This may particularly apply when the robot is a supportive companion [16] that is intended to change the user's state; the robot's behavior likely will be much more effective if it first attempts to build a trustworthy, empathetic relationship with the user [12].

\subsection{Human-Robot Bonding}

People use numerous behaviors to both establish and maintain relationships (e.g., romantic, friendship, colleague) with each other. Many of such behaviors can be emulated by robots, in order to form social-emotional human-robot relationships [12,75]; particularly because people employ heuristics derived from human-human interaction when they interact with robots $[29,106]$. For extensive overviews of human-human and human-robot relationships, we refer to: $[12,29,86]$. Human relationships typically evolve over time, and this likely applies for human-robot relationships as well $[12,86]$. Some researchers even suggest that it is not possible to create a constructive human-robot relationship in a short period of time $[8,30]$. While this may be true for more intimate types of relationships with robots, various studies have demonstrated that emulation of different human relational strategies by social robots can create a sense of social presence [84], and in turn can establish rapport and acquaintance 
between human and robot, even in short-term interactions $[66,79,87,96,104]$.

\section{The Current Study}

In the study as described here, half of the participants will establish a social bond with a social robot, which allows us to investigate the modulating effects of this bond on the participant's responses to robot-initiated touches. The bond is supposed to be formed during a single-session interaction in which the robot emulates various relational strategies that are derived from human-human interaction. The robotinitiated touch interaction (or its No Touch counterpart) takes place in a stressful setting; the same scary movie paradigm as applied in earlier research [135]. Social touch has proven to be effective during stressful tasks, and the use of videos is a well-established method of stress elicitation (e.g., [78]). With regard to the responses to touch, we specifically focus on the stress-attenuating, the relationship-enhancing, and the prosocial behavior-increasing effects that are known for touch and that have been discussed in Sect. 2.1. Each of these three 'generic touch effects' is operationalized by multiple conceptually related dependent variables that are derived from earlier social touch or HRI research, or which were deemed relevant for this specific study. These objective and subjective measures are jointly analyzed with Multivariate ANOVAs, in order to provide robust insights regarding the generic touch effects [38, p. 586].

Based on the literature on the effects of human social touch and the modulating effects of a social relationship (see Sects. 2.1 and 2.2), as well as on the CASA paradigm that poses that people respond similarly to computers as they would to other people (see Sect. 2.3), we defined the following hypotheses:

H1a Being touched by a robot will have beneficial effects on the participant's arousal level in stressful circumstances, as compared with not being touched. More specifically, less steep increases in heart rate, galvanic skin response, and respiration rate are expected following a robot's touch, as well as a smaller decrease in heart rate variability. These objective physiological stress-responses are expected for the entire duration of the movie as well as for each of the eight touch interactions separately. Moreover, smaller increases in negative affect and arousal, as well as smaller decreases in positive affect and valence (i.e., subjective stress-related self-report measures) are expected due to the touch. Finally, the movies are expected to elicit less fear and disgust arousal when the participant is touched by the robot.
H1b A robot's touch will strengthen one's perceived relationship with it, as compared with an interaction without physical contact. We expect touch to increase scores on a selection of relational self-reports (i.e., affective and perceived trust, intimacy, stimulating companionship, emotional security, and helpfulness).

H1c A robot-initiated touch can induce a Midas Touch effect and will thus increase the participant's pro-social behavior. This will be reflected in an increased willingness to comply with the robot's requests to donate money to ostensibly enable future robot research and to stay extra time for additional questionnaires.

H2 Both the stress-attenuating effects (H1a) and the perceptions of the relation with the robot $(\mathrm{H} 1 \mathrm{~b})$ will be stronger when a positive social relationship with the robot is established prior to the touch interaction. ${ }^{1}$

To gain more insights in possible opportunities and limitations of robot-initiated touch, we also carry out several additional explorative analyses regarding how touch affects the perceived appearance of the robot and one's attitude towards robots in general. Moreover, we investigate whether having a bond with a robot makes robotic touches more appropriate.

\section{Methods}

We devised a $2 \times 2$ between subjects experiment (i.e., four groups) with Bonding (levels: Bond, No Bond) and Touching (levels: Touch, No Touch) as independent variables. The experiment consisted of two phases. In phase 1 (the bonding phase), participants either engaged in interactions with a social robot in order to form a bond with it (Bond groups), or with the experiment leader during which no bond with the robot was formed even though it was present and moving idly (No Bond groups). In phase 2 (the movie viewing phase), participants watched a scary movie with the robot that occasionally spoke soothing words that were either accompanied by a social touch in the Touch groups, or not (No Touch groups). Unknown to the participants, the robot was not autonomous, but remotely controlled.

\subsection{Participants}

A total of 67 participants $($ mean age $=47.9, S D=20.0$, range $=$ $18-78,49.3 \%$ female) was recruited from the TNO database and randomly assigned to one of the four groups: BondTouch ( 7 female, 8 male), Bond-No Touch $(8,9)$, No BondTouch $(10,8)$, and No Bond-No Touch $(8,9)$. The sample

\footnotetext{
1 The pro-social behavior (H1c) is not expected to be modulated by the bond, as Midas Touch effects also appeared when strangers-either humans (e.g., $[27,47])$ or robots (e.g., $[95,118]$ )—applied the touch.
} 


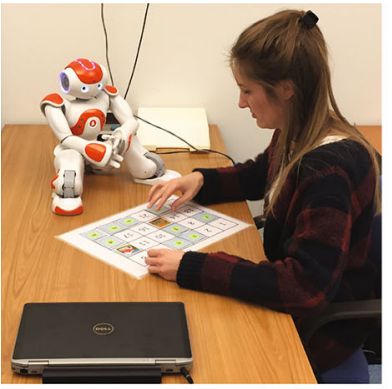

(a)

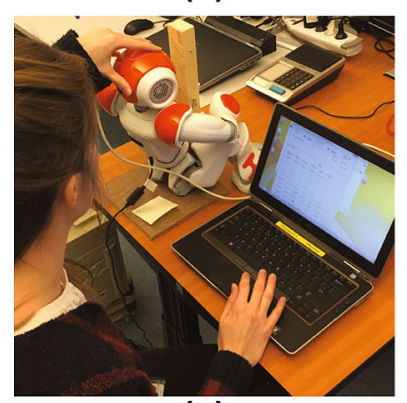

(c)

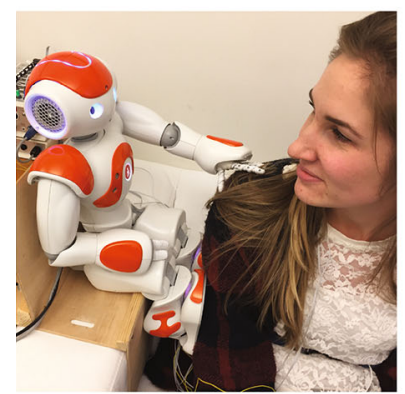

(e)

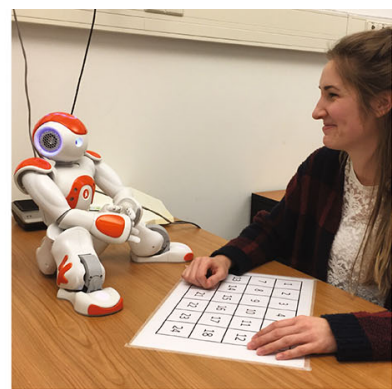

(b)

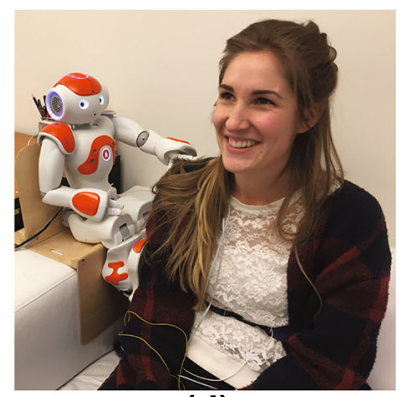

(d)

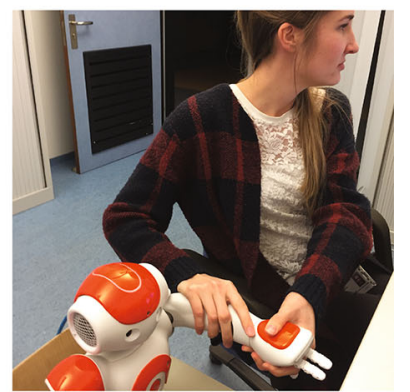

(f)
Fig. 1 Impression of the experimental setting (no actual participant and experimenter depicted). a Memory game. b Conversation. c Remotely controlling the bonding interaction by the experimenter through the master robot and a graphical user interface to play the voice files. d, e Robot-initiated touch. f Remotely controlling the touches of the slave robot by the experimenter, by moving the master robot's arm and head

size was determined by a power-analysis through $\mathrm{G} *$ Power [35], with the power $(1-\beta)$ set to the recommended 0.8 and the effect size $f^{2}$ to 0.15 (i.e., medium) [22]. According to the power analysis, a sample size of 64 was required for a twoway MANOVA with 6 dependent variables. All participants had normal or corrected to normal vision and hearing. The study was reviewed and approved by the TNO institutional review board (TNO, Soesterberg), and was in accordance with the Helsinki Declaration of 1975, as revised in 2013 [137]. Participants received $€ 30$,- for their participation.

\subsection{Setting and Materials}

An overview of the setting is depicted in Fig. 1. The experiment took place in a $15 \mathrm{~m}^{2}$ room. During the bonding phase (phase 1), participants sat at a table with a "NAO" $\operatorname{robot}^{2}(\mathrm{v} 4$, NAOqi 1.12.5) on it. For phase 2, they moved to a couch to watch a scary movie, where the robot would sit on the righthand side's armrest. The NAO robot in the lab (referred to as the 'slave' robot) was connected to a second NAO robot in an adjacent control room (referred to as the 'master' robot). Changes in the positions of the limbs and head of the master robot, which were carried out by a trained experimenter, were reproduced by the slave robot. Pre-programmed sentences and responses were initiated manually, utilizing the Acapela Femke Dutch Female 22 kHz Text-to-Speech converter $^{3}$ with $20 \%$ increase in speech velocity and pitch. To control the dialogue in the bonding phase, the selection of the robot's verbal responses to the participants was based on a pre-defined decision tree. The robot's utterances in the movie phase were fully scripted.

Participants in the Bond groups engaged in HRI during which the robot displayed a variety of verbal and nonverbal relational strategies which are listed in Table 1 . The activities comprised small talk (e.g., about the participant's experiences with experiments), a competitive game of Memory, a collaborative multiple choice knowledge quiz, and the sharing of personal stories. Participants in the No Bond groups carried out the same activities, albeit with the experiment leader as communication partner instead of the robot. The robot was sitting at the same location on the table however, and displayed random idle movements to let the participant get used to its appearance in order to decrease potential startling responses in the movie phase due to unanticipated movements of the robot.

At eight pre-determined moments during movie viewing (phase 2) and only in the Touch groups, the experimenter initiated social touches through the master robot. The slave robot in the lab extended its left arm towards the participant's right shoulder and upper arm (in approximately $5 \mathrm{~s}$ ). Subsequently, physical contact occurred (for the eight moments, the duration of the physical contact varied between 10 and $40 \mathrm{~s}$ ). Due to the master-slave setup, in which the robot's motors provided continuous pressure, the touch was gentle, but clearly perceptible. During the final part of the physical contact, the robot spoke calming words, after which it moved its arm to the initial position (in $5 \mathrm{~s}$ ). The hand on the shoulder is an often-applied means to provide comfort in human touch interactions [34] and as such it was deemed a suitable touching action for our study as well; in particular because it could be applied despite the robot's limited reach. Moreover, a hand on the shoulder was considered an appropriate and acceptable form of physical contact (contrary to for example a touch on the head or thigh). In the No Touch groups, the robot moved its head and arms without making physical con-

\footnotetext{
2 https://www.ald.softbankrobotics.com/en/robots/nao.

3 http://www.acapela-group.com, visited: Aug. 9th, 2017.
} 
Table 1 Overview of the relational strategies that were applied in the current experiment, supplemented with examples of related HRI research in which the strategies were successfully applied

\begin{tabular}{ll}
\hline Relational strategy & Operationalization \\
\hline $\begin{array}{l}\text { Verbal communication } \\
\text { Phatic expression }[62,116]\end{array}$ & $\begin{array}{r}\text { The robot and participant engaged in small talk about the participant's experiences with regard to experiment } \\
\text { participation in general, and with robots. Phatic communication is supposed to build rapport by increasing } \\
\text { familiarity and establishing common ground }\end{array}$ \\
$\begin{array}{l}\text { Social deixis }[82,88] \\
\text { In HRI: }[67,72,113]\end{array}$ & $\begin{array}{l}\text { The participant was addressed with his/her first name, and the robot's language was informal; the participant was } \\
\text { considered a peer. No hierarchical relationship, but a small social distance was implied by the use of the } \\
\text { language }\end{array}$ \\
$\begin{array}{l}\text { Flattering }[17] \\
\text { In HRI: }[31,106]\end{array}$ & $\begin{array}{c}\text { The participant was complimented on his/her knowledge and memory skills during the activities, in order to } \\
\text { make the robot more likable }\end{array}$ \\
Politeness $[17]$ & $\begin{array}{r}\text { For practical reasons, different databases with pre-programmed sentences were created for different tasks. These } \\
\text { In HRI: }[28,29,31]\end{array}$
\end{tabular}
prior to each database switch

Greetings [17]

In HRI: [44]

The participant was greeted at several moments during the bonding phase. E.g., at the start of the interaction, and around the speech-set switches

\section{Nonverbal behavior}

Physical contact $[40,51]$

In HRI: [42,60,95,98,118]

Immediacy [4]

In HRI: [12,31]

Joint attention [71]

In HRI: [74,108]

\section{Relational dynamics}

Self-disclosure [24,81]

In HRI: $[66,79,94]$

Empathy [20,107]

In HRI: [12,87]

Help, altruism [77]

In HRI: [45,110]

Collaboration $[12,123]$

In HRI: [41,96,117]
After the bonding phase, the participant carried the robot from the table to its chair on the couch, in anticipation of the movie viewing. Physical contact supposedly enhances a bond, and carrying the robot draws upon the participant's altruistic behavior towards the robot

The robot gestured with its arms during speech, while its gaze (i.e., facial orientation) was directed at the participant. While 'listening' to the participant, the robot nodded from time to time. In general, the robot had an open body posture. Immediacy behaviors suggest liking for the other and engagement in the interaction

The robot's gaze (i.e., facial orientation) switched from the participant to the task at hand (e.g., the memory game or quiz) and vice versa, in order to provide mutual acknowledgement that they are attending to the same target

The robot tells a personal story about a colleague at TNO that has been in an accident, and about how the robot felt about this. The willingness to share personal information implies trust in the other and supposedly increases the bond

The robot attended to the participant's responses to questions on what (s)he thought or felt about certain topics or situations throughout the study. The robot responded in an understanding way. Empathetic behavior is at the essence of bonding

The robot asked the participant to turn the Memory cards, while playing competitively. Moreover, the robot asked the participant to carry it to the couch for the second experimental phase in order to elicit altruistic behavior in the participant.

The robot and participant collaborated as a team in answering the questions of the knowledge quiz. Being part of the same team implicitly enhances the sense of a bond tact with the participant. These idle movements were again carried out to compensate for potential startling responses due to sudden movements of the robot.

Two short thrilling movies, "The Descendent" [2] and "Red Balloon" [127], were played consecutively (excluding introductory credits; total duration 26:36). The movies were projected $(1280 \times 1024$ pixels $)$ on a white wall (approximately $2 \times 1.4 \mathrm{~m}, 2.5 \mathrm{~m}$ from the viewer), with speakers on both sides of the screen. These movies, which were successfully applied in earlier research [135] were selected as they continuously build up excitement and contain multiple startling scenes, without depicting possibly disturbing 


\begin{tabular}{|c|c|c|c|c|}
\hline $\mathrm{Q}$ & & & 22 & P2 \\
\hline $\begin{array}{l}\text { Bonding } \\
\text { Social Closeness } \\
\text { Likability } \\
\text { Anthropo- } \\
\text { morphism }\end{array}$ & $\begin{array}{l}\text { Covariates and } \\
\text { Demographics } \\
\text { Age } \\
\text { Gender } \\
\text { Robot Anxiety } \\
\text { Robot Attitude } \\
\text { Negative Attitude } \\
\text { towards Robots }\end{array}$ & $\begin{array}{l}\text { Bonding } \\
\text { Social Closeness } \\
\text { Likability } \\
\text { Anthropomorphism } \\
\text { Attachment } \\
\text { Self-Disclosure } \\
\text { Social Presence }\end{array}$ & $\begin{array}{l}\text { Emotional State } \\
\text { Valence } \\
\text { Arousal } \\
\text { Positive Affect } \\
\text { Negative Affect }\end{array}$ & \begin{tabular}{|l|} 
Baseline \\
GSR \\
HR (+ Variability) \\
Respiration Rate \\
Emotional State \\
GSR \\
HR (+ Variability) \\
Respiration Rate
\end{tabular} \\
\hline
\end{tabular}

\begin{tabular}{|llll|}
\hline \multicolumn{4}{|c|}{ Q3 } \\
\hline Robot Relation & Emotional State & Bonding & Appearance \\
Affective Trust & Valence \& Arousal & Social Closeness & Immediacy \\
Perceived Trust & Positive Affect & Likability & Safety \\
Helpfulness & Negative Affect & Anthropo- & Qualification \\
Intimacy & Fear Arousal & morphism & Dynamism \\
Emotional & Disgust Arousal & Attachment & Robot Attitude \\
Security & Midas Touch & Touch Perception & Negative Attitude \\
Stimulating & Donated Money & 5 Questions & towards Robots \\
Companionship & Time Available & & \\
\hline
\end{tabular}

Fig. 2 Overview of the questionnaires (Q), the associated measures, and moments of application. P1 refers to phase 1 (bonding manipulation) and $\mathrm{P} 2$ to phase 2 (movie viewing, including baseline and scary movies)

explicit scenes. Playing the movies in their entirety was deemed necessary to elicit a lasting thrill, and thus to create an appropriate setting for supposedly comforting robot-initiated touches. As suggested by Piferi and colleagues [105], a 3-min excerpt from a neutral aquatic movie, "Coral Sea Dreaming: Awaken" [55] was displayed during the physiological baseline recordings prior to the scary movies. Physiological state recordings were made with Actiview 7.06 software $(2048 \mathrm{~Hz})$, to which synchronization markers for the movie and interaction events were added automatically. BioSemi ActiveTwo ${ }^{4}$ flat $\mathrm{Ag}-\mathrm{AgCl}$ electrodes, passive Nihon Kohden electrodes, and the Sleep-Sense 1387-kit were used to measure cardiac activity, Galvanic Skin Response, and respiration, respectively.

\subsection{Measures}

An overview of all measures, as well as the moments at which these were administered is provided in Fig. 2.

\subsubsection{Phase 1: The Bonding Manipulation}

To verify whether the bonding manipulation was effective, participants were asked to indicate the perceived Social Closeness (Inclusion of Other in Self; IOS [5]), Likability, and Anthropomorphism of the robot (i.e., Godspeed questionnaire subscales [7]), both prior to and after the first phase of the study. In addition, the Social Presence [84] and Attachment [115] questionnaires were administered after the bonding interaction. Finally, one's Reciprocal SelfDisclosure was measured by the extent to which a participant was willing to talk about two lowly, two moderately, and two highly intimate conversation topics, derived from [102], with the robot. The six Self-Disclosure scores $(1=$ "No problem to talk about this topic", $7=$ "This topic is too intimate") were summed.

\footnotetext{
${ }^{4}$ http://www.biosemi.com, last visit: August 9th, 2017.
}

\subsubsection{Phase 2: The Responses to Robot-Initiated Touch}

Emotional State To investigate the effects of a robot's touch on one's arousal level, the Galvanic Skin Response (GSR), Heart Rate (HR), Heart Rate Variability (HRV), and Respiration Rate (RR) were recorded both during a baseline recording while watching the neutral movie, and during the scary movies. GSR, with electrodes on the palm and on the first lumbrical muscle of the left hand, increases linearly with arousal [80]. Moreover, when emotional intensity increases, HR increases [91] and HRV-i.e., the temporal differences between successive inter-beat intervals in the ECG wave [124], operationalized by the Root Mean Square of Successive Differences (RMSSD)—decreases. The cardiac measures were recorded with electrodes on the right clavicle and left floating rib. Finally, RR-which increases with emotional arousal [121] —was measured with an elastic belt around the thorax, directly below the sternum. For each measurement, a 2-min baseline recording was made during the neutral movie, as well as a recording throughout the scary movies. The average physiological values were computed for (1) the entire scary movie sequence excluding the nonscary introductory scenes (duration: 20:04), (2) the eight interaction moments ( $+45 \mathrm{~s}$ after interaction offset; 10:16), and (3) the intervals in between these interaction moments (09:48). In addition, we analyzed the responses at each of the eight interaction moments $(+45 \mathrm{~s})$ separately. The participants indicated their Valence and Arousal (Self-Assessment Manikin; SAM [13]), and Positive and Negative Affect (a Dutch translation [103] of the Positive and Negative Affect Schedule; PANAS [132]) both prior to and after the movies. After the movies, participants filled out a selection of items of the Fear Arousal Scale (FAS) and Disgust Arousal Scale (DAS) [109] for both scary movies to investigate how the stressors were perceived. The FAS and DAS scores of both movies were aggregated into a single FAS and DAS score, respectively.

Relation with the Robot To verify whether robot-initiated touches enhanced the perceived relation with the robot, we administered the Affective Trust (adopted from [63], as applied in [73]), Perceived Trust (based on [32], as applied 
in $[69,112]$ ), and Perceived Friendship (i.e., the Help, Intimacy, Emotional Security, and Stimulating Companionship subscales [104]).

Pro-social Behavior To investigate whether a Midas Touch effect can also be achieved in HRI, participants were asked how much of their $e$ 30,- compensation they would like to donate to support additional robot research. Moreover, participants were asked how long they were willing to stay to fill out additional questionnaires (similar to [101]). For both (bogus) requests we recorded the proportion of people that complied, as well as the actual amount of money or time made available.

\subsubsection{Exploratory Measures and Covariates}

Besides the age and gender of the participants, we assessed the participant's Anxiety to the robot's communication capabilities, its behavioral characteristics, and its discourse with the Robot Anxiety Scale (RAS; [99]), as these subscales may influence the bonding and/or the perceptions of the touches. To gain further insights in the effects of robot-initiated touches on the human recipient, we investigated whether touches (and bonding) affected perceptions of the robot's appearance. Participants filled out self-reports regarding the robot's perceived Safety, Qualification, and Dynamism (i.e., subscales of the Credibility scale [69]; based on the Source Credibility scale [10]), and Immediacy ([1], as described in $[69,112])$. Moreover, we investigated whether being touched by a robot (and bonding with it) affects one's "Negative Attitude Towards Robots", by using the accompanying NARS-scale [99]. This scale comprises three subscales (Negative attitude towards interaction with, social influence of, and emotional interactions with robots) which were administered both prior to the bonding phase, and after the movie phase. Finally, we checked whether the participants did perceive the touches as a control question (yes/no), and whether the touch was perceived as (1) intended to be calming, (2) actually calming, (3) appropriate, (4) startling, and (5) humanlike ( 1 = "Totally Agree", 7 = "Totally Disagree"). The latter was intended to gain additional insights in whether bonding affects touch perceptions.

\subsection{Procedure}

Participants were invited in the lab room, where the robot and the ostensible aim of the study-paraphrased: "investigating whether the robot can detect the participant's behavior and emotional state, and can behave accordingly"-were introduced. The participant was asked to fill out a first questionnaire (Fig. 2, Q1) before engaging in the bonding interaction (small talk, the memory game, the quiz, and listening to the personal story) with the robot (Bond) or the experiment leader (No Bond; the robot displayed random idle movements). After the interaction, a second questionnaire (Fig. 2, Q2) was administered. In the Bond groups, the participant was asked to carry the robot to its seat on the couch, whereas the experiment leader carried it in the No Bond conditions. After attaching the electrodes for the physiological recordings, the experiment leader left, and the participant watched the baseline movie and the scary movies, during which the eight interactions with the robot (either with or without touch) took place. Subsequently, the final questionnaire (Fig. 2, Q3), including the request for a donation, was filled out. When the participant finished the questionnaire, the experiment leader returned, detached the electrodes, and asked the participant whether (s)he was willing to stay for additional questionnaires. After this final measure, the participant was fully debriefed and thanked.

\section{Results}

\subsection{Pre-processing}

Due to a technical problem during the movie, and due to missing responses, data of two participants were omitted from all analyses. None of the participants was familiar with either of the movies and none of the participants in the Touch groups missed the fact that they were touched by the robot. Five people in the No Touch groups indicated to be touched by the robot-likely due to the fact that they were sitting against the robot's feet. Their data were included in the analyses, as omission did not result in a different interpretation of the effects. All dependent variables were tested for normality, and transformed when the normality assumption was violated. When transformation did not yield a normal distribution, we opted for a non-parametric statistical test. The division of the 65 participants with valid data was 15 (BondTouch), 16 (Bond-No Touch), 18 (No Bond-Touch), and 16 (No Bond-No Touch). Significance is reported at the $p=.05$ threshold.

The physiological recordings were processed in MATLAB R2013b ${ }^{5}$ with the FieldTrip toolbox [100]. A Fast Fourier Transform was applied on the ECG to remove the low-frequency components, after which the HR and HRV (RMSSD) were derived for the baseline period, the movie, the interaction moments, and the non-interaction intervals by means of a peak-detection algorithm. Range correction was applied on the GSR data [90] prior to the computation of the scores for each of the intervals. A 2nd-order low-pass Butterworth filter was applied to remove the high frequency component in the respiration recordings. The respiration rates were determined with a peak-detection algorithm on the filtered signal. Due to technical problems, physiological data

\footnotetext{
${ }^{5}$ http://www.mathworks.com, last visit: August 9th, 2017.
} 
of 5 participants were omitted from the Emotional State analyses. For 13 participants, one of the physiological recordings (ECG, GSR, or RR) was invalid. Data imputation by means of group mean substitution was applied for these cases, in order to retain their remaining valid data, and thus to circumvent listwise exclusion during the analyses. Group mean substitution is a rather conservative approach. In the Emotional State analyses, the Bond-Touch, Bond-No Touch, No Bond-Touch, and No Bond-No Touch groups comprised of $15,14,16$, and 15 participants, respectively.

\subsection{Manipulation Checks}

To investigate whether the relational strategies in phase 1 indeed enhanced the bond between participant and robot, a one-way MANCOVA was carried out with Bonding as between groups independent variable (IV), Anxiety to the robot's communication capabilities as covariate, and the bonding measures (the difference scores of the Likability and Anthropomorphism scales, and the post bonding phase measures Attachment, Self-Disclosure, and Social Presence) as dependent variables (DVs). Data of 65 participants were included. The covariate was a significant predictor of the effects: Wilks' $\Lambda=.689, F_{(5,58)}=5.23, p=.001$, partial $\eta^{2}=.311$. The results suggest that the bonding manipulation worked as intended: Wilks' $\Lambda=.611, F_{(5,58)}=7.34, p<.001$, partial $\eta^{2}=.389$. Inspection of the individual ANCOVAs revealed significant positive effects of bonding on Likability ( $\triangle$; Bond: $M=0.31$ (SD = 0.48), No Bond: -0.07 (0.42), $p=.002$ ), Attachment (Bond: 2.94 (0.80), No Bond: 2.35 (0.67), $p=.002$ ), and Social Presence (Bond: 5.72 (1.57), No Bond: 3.77 (1.54), $p<.001)$. The levels of perceived Anthropomorphism and Self-Disclosure were not affected by the bonding manipulation. Although the age of the participant (as a proxy for affinity with robots) often modulates how interactions with social robots are perceived, this was not the case with the several bonding scores. Age is therefore not further reported. A Mann-Whitney U test was performed on the IOS difference score, with Bonding as independent variable. This test yielded a significant effect of Bond (mean ranks: 42.44) over No Bond (24.40) on Social Closeness: $U$ $=234.5, Z=-4.173, p<.001$.

To verify whether the movie indeed was stressful, we conducted a one-way repeated measures MANOVA with Measurement Moment (Baseline, Movie) as within subjects independent variable. As dependent variables, the physiological measures (HR, HRV ( $\log _{10}$ transformed), GSR (square root transformed), and RR) were included, as well as the Positive Affect score. Data from the 60 participants with valid physiological responses were included. The analysis yielded a significant main effect of Measurement Moment, which implies differences in stress responses between the Movie and the Baseline: Wilks' $\Lambda=.227, F_{(5,55)}=37.41, p$
$<.001$, partial $\eta^{2}=.773$. Further inspection of the individual Repeated Measures ANOVAs yielded a significant increase of GSR (Baseline: 0.35 (0.17), Movie: 0.64 (0.09), $p<.001$ ) and a significant decrease of Positive Affect (Baseline: 33.71 (5.74), Movie: 27.93 (3.04), $p<.001)$ due to the movie. Figure 3 depicts the physiological responses of one specific participant.

Wilcoxon Signed Ranks tests showed that the Movie score for Valence $(5.57(1.65))$ was significantly lower than the Baseline score (7.13 (1.16)) and that the movie significantly increased Arousal (Baseline: 2.38 (1.60), Movie: 4.05 (1.90)) and Negative Affect (Baseline: 12.22 (3.59), Movie: 17.66 (6.77)); all $\mathrm{ps}<.001$. Aforementioned analyses demonstrate that the bonding manipulation and the stress elicitation worked as intended.

\subsection{Touch Effects}

We conducted a series of two-way MANOVAs with Bonding (Bond, No Bond) and Touching (Touch, No Touch) as between subjects IVs, and the Emotional State and Robot Relation measures as DVs. We list all main and interaction effects of the MANOVAs in Table 2, after which we address the significant effects separately.

\subsubsection{Emotional State}

As can be seen in Table 2, no effects of Touching and/or Bonding were found on the overall Emotional State measures. However, when looking at the direct physiological responses to robot-initiated touches-i.e., the aggregated physiological values for the eight interaction moments minus their baseline counterparts - a trend became apparent for Touching $(p=.056)$. Further inspection of this trend demonstrated a significant difference on the Heart Rate. Whereas the HR increased over time for people in the No Touch groups, it decreased for people in the Touch groups: $F_{(1,56)}=5.99$, $p=.018$, partial $\eta^{2}=.097$. When zooming in on each individual interaction moment (+ additional 45 s; see Fig. 4), it becomes apparent that the difference mostly appears during the second movie. A similar pattern emerged when looking at the physiological responses during the intervals between the interaction moments. The significant main effect for Touching ( $p=.037)$ was reflected in the HR, which increased for people in the No Touch groups and decreased for participants in the Touch groups: $F_{(1,56)}=5.93, p=.018$, partial $\eta^{2}=.096$. An overview of the physiological responses can be found in Table 3.

\subsubsection{Robot Relation}

The MANOVA with the relational measures (see Table 2) suggests a significant main effect of Touching. According 


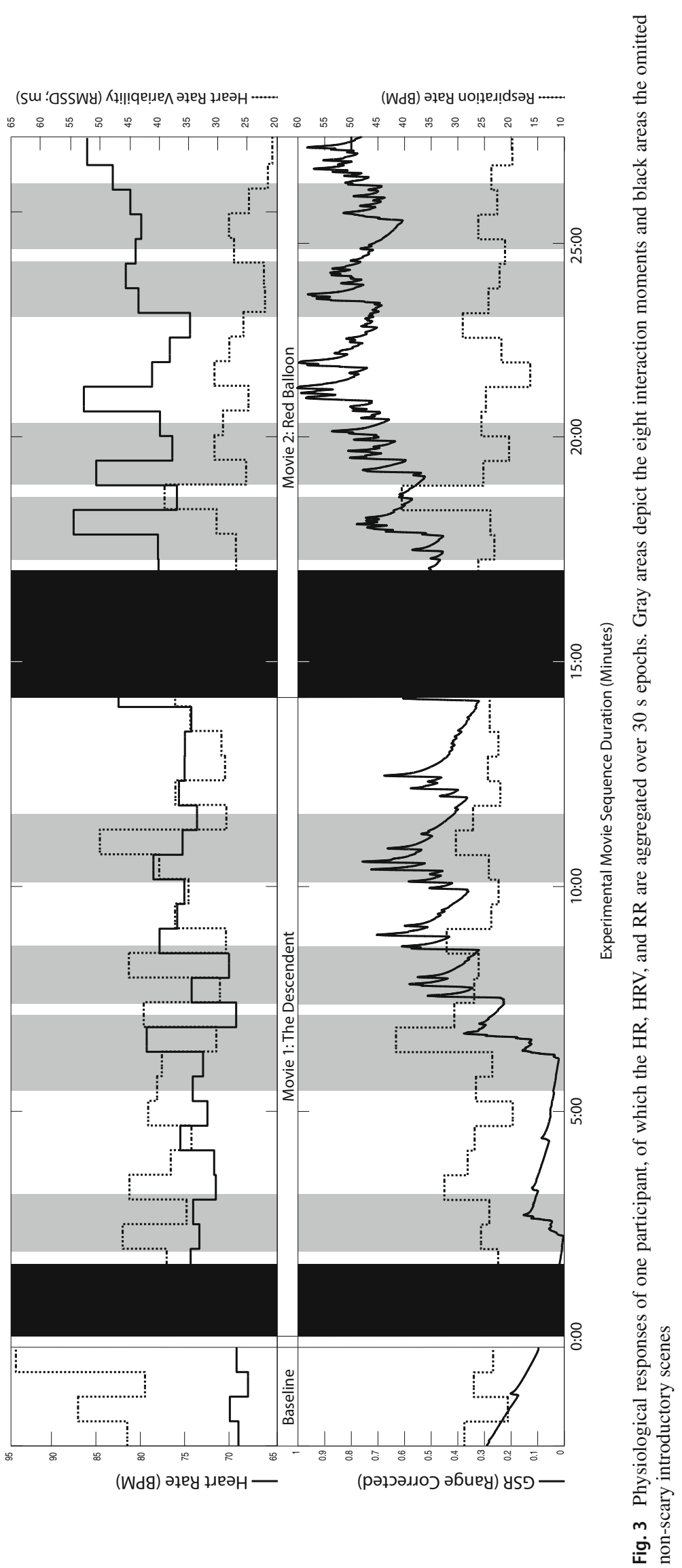


Table 2 Overview of the main and interaction effects of the MANOVAs

$$
\text { Wilks' } \Lambda \quad \text { df } \quad F \quad p
$$

Partial $\eta^{2}$

Emotional state, entire movie $(n=60)$ : $\operatorname{GSR}(\Delta), \operatorname{HR}(\Delta), \operatorname{HRV}(\Delta), \operatorname{RR}(\Delta)$, valence $(\Delta)$, arousal $(\Delta)$, positive affect $(\Delta)$, negative affect $(\Delta)$, fear arousal scale, disgust arousal scale

$\begin{array}{llllll}\text { Main effect touching } & .727 & (10,47) & 1.76 & .095 & .273 \\ \text { Main effect bonding } & .911 & (10,47) & 0.46 & .907 & .089 \\ \text { Interaction touching } \times \text { bonding } & .891 & (10,47) & 0.57 & .826 & .109\end{array}$

Emotional state, interaction moments $(n=60)$ : GSR $(\Delta), \operatorname{HR}(\Delta), \operatorname{HRV}(\Delta), \operatorname{RR}(\Delta)$

$\begin{array}{llllll}\text { Main effect touching } & .843 & (4,53) & 2.46 & \mathbf{. 0 5 6}(*) & .157 \\ \text { Main effect bonding } & .984 & (4,53) & 0.22 & .926 & .016 \\ \text { Interaction touching } \times \text { bonding } & .959 & (4,53) & 0.56 & .692 & .041\end{array}$

Emotional State, non-interaction intervals $(n=60)$ : GSR $(\Delta), \operatorname{HR}(\Delta), \operatorname{HRV}(\Delta), \operatorname{RR}(\Delta)$

$\begin{array}{llllll}\text { Main effect touching } & .828 & (4,53) & 2.76 & \mathbf{. 0 3 7} * & .172 \\ \text { Main effect bonding } & .996 & (4,53) & 0.05 & .995 & .004 \\ \text { Interaction touching } \times \text { bonding } & .950 & (4,53) & 0.69 & .600 & .050\end{array}$

Robot relation $(n=65)$ : affective trust, perceived trust, help, intimacy, emotional security, and stimulating companionship

$\begin{array}{llllll}\text { Main effect touching } & .790 & (6,56) & 2.48 & . \mathbf{0 3 4} * & .210 \\ \text { Main effect bonding } & .909 & (6,56) & 0.93 & .478 & .091 \\ \text { Interaction touching } \times \text { bonding } & .951 & (6,56) & 0.48 & .820 & .049\end{array}$

$\Delta$-values indicate differences between post-movie and pre-movie scores. Bold-faced, $*$-marked values indicate significant effects, and $(*)$ a trend

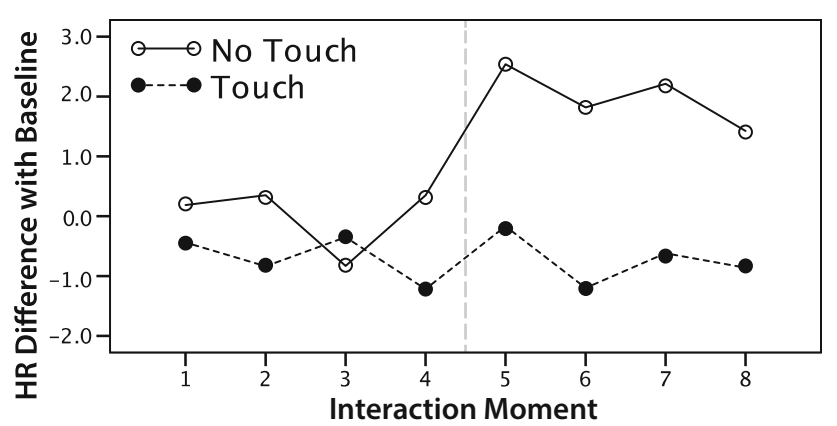

Fig. 4 Heart rate values $(\Delta)$ for the eight interaction moments, per touching condition. The dashed line indicates the start of the second movie

to the separate ANOVAs and the group means, people in the Touch groups perceived a stronger sense of Intimacy with the robot than people in the No Touch groups: $F_{(1,61)}=4.33, p=$ .042 , partial $\eta^{2}=.066$. The scores of all dependent variables are listed in Table 4.

\subsubsection{Midas Touch Effect}

To investigate whether a robot-initiated touch could induce a Midas Touch effect, we carried out a Mann-Whitney U test on the amount of money that was donated. To this end, we compared the Touch $(M=€ 3.98(S D=6.72))$ with the No Touch (€4.62 (7.81) groups, regardless of the Bonding. No significant Midas Touch effect was observed for the donation measure: $U=527.5, Z=-.008, p=.994$. Moreover, a $\chi^{2}$ test to investigate whether the actual willingness to donate differed between people in the Touch (33\% donated) and No Touch $(37.5 \%)$ groups, did not demonstrate any differences: $\chi^{2}(1, n=65)=0.123, p=.798$ (2-sided).

A similar Mann-Whitney U analysis was carried out on the data of 61 participants (due to missing data) to scrutinize the willingness to stay extra time for ostensible additional experimental tasks. No significant difference between the Touch (25.3 $\min$ (17.8) and No Touch (25.4 $\min$ (16.7) groups was found: $U=444.0, Z=-0.301, p=.764$. Since 58 out of the 61 participants were willing to stay longer, no additional $\chi^{2}$-test was carried out.

\subsection{Data Exploration}

\subsubsection{Touch and Bonding}

To gain additional insights in the opportunities and limitations of robot-initiated touch and the possibly modulating role of bonding, we carried out several exploratory analyses. Additional two-way MANOVAs were carried out for the Robot Appearance and Attitude measures, whereas a one-way MANOVA with Bonding (Bond, No Bond) as independent between subjects variable was intended to provide insights in the Touch Appropriateness scores. A $2 \times$ $2 \times 2$ mixed-model MANOVA with Bonding, Touching, 
Table 3 Mean physiological responses $(S D)$ and differences with baseline $(\Delta,(S D))$ per recording interval
Table 4 Descriptives and statistics of the robot relation scores

\begin{tabular}{|c|c|c|c|c|c|c|c|}
\hline & \multirow[t]{2}{*}{ Baseline } & \multicolumn{2}{|l|}{ Movie } & \multicolumn{2}{|c|}{ Interaction moments } & \multicolumn{2}{|c|}{ Non-interactions } \\
\hline & & Value & $\Delta$ & Value & $\Delta$ & Value & $\Delta$ \\
\hline \multicolumn{8}{|l|}{ HR } \\
\hline Touch & $\begin{array}{l}68.23 \\
(9.81)\end{array}$ & $\begin{array}{l}67.17 \\
(9.27)\end{array}$ & $\begin{array}{l}-1.06 \\
(2.28)\end{array}$ & $\begin{array}{l}67.51 \\
(9.45)\end{array}$ & $\begin{array}{l}-0.72 \\
(2.29)\end{array}$ & $\begin{array}{l}67.63 \\
(9.61)\end{array}$ & $\begin{array}{l}-0.59 \\
(2.37)\end{array}$ \\
\hline No Touch & $\begin{array}{l}68.55 \\
(10.31)\end{array}$ & $\begin{array}{l}68.92 \\
(10.22)\end{array}$ & $\begin{array}{l}0.37 \\
(3.16)\end{array}$ & $\begin{array}{l}69.63 \\
(10.01)\end{array}$ & $\begin{array}{l}1.08 \\
(3.26)\end{array}$ & $\begin{array}{l}69.70 \\
(10.24)\end{array}$ & $\begin{array}{l}1.15 \\
(3.04)\end{array}$ \\
\hline \multicolumn{8}{|l|}{ HRV } \\
\hline Touch & $\begin{array}{l}36.71 \\
(26.43)\end{array}$ & $\begin{array}{l}29.16 \\
(17.52)\end{array}$ & $\begin{array}{l}-7.55 \\
(14.78)\end{array}$ & $\begin{array}{l}30.38 \\
(18.09)\end{array}$ & $\begin{array}{l}-6.33 \\
(17.00)\end{array}$ & $\begin{array}{l}29.87 \\
(17.97)\end{array}$ & $\begin{array}{l}-6.84 \\
(13.23)\end{array}$ \\
\hline No Touch & $\begin{array}{l}37.12 \\
(24.60)\end{array}$ & $\begin{array}{l}38.08 \\
(20.64)\end{array}$ & $\begin{array}{l}0.95 \\
(18.53)\end{array}$ & $\begin{array}{l}34.28 \\
(19.10)\end{array}$ & $\begin{array}{l}-2.84 \\
(13.47)\end{array}$ & $\begin{array}{l}33.54 \\
(17.98)\end{array}$ & $\begin{array}{l}-3.58 \\
(11.93)\end{array}$ \\
\hline \multicolumn{8}{|l|}{ GSR } \\
\hline Touch & $\begin{array}{l}0.15 \\
(0.15)\end{array}$ & $\begin{array}{l}0.41 \\
(0.10)\end{array}$ & $\begin{array}{l}0.26 \\
(0.20)\end{array}$ & $\begin{array}{l}0.42 \\
(0.10)\end{array}$ & $\begin{array}{l}0.26 \\
(0.19)\end{array}$ & $\begin{array}{l}0.41 \\
(0.10)\end{array}$ & $\begin{array}{l}0.25 \\
(0.20)\end{array}$ \\
\hline No Touch & $\begin{array}{l}0.15 \\
(0.13)\end{array}$ & $\begin{array}{l}0.42 \\
(0.12)\end{array}$ & $\begin{array}{l}0.27 \\
(0.20)\end{array}$ & $\begin{array}{l}0.42 \\
(0.13)\end{array}$ & $\begin{array}{l}0.27 \\
(0.20)\end{array}$ & $\begin{array}{l}0.42 \\
(0.12)\end{array}$ & $\begin{array}{l}0.27 \\
(0.20)\end{array}$ \\
\hline \multicolumn{8}{|l|}{$\mathbf{R} \mathbf{R}$} \\
\hline Touch & $\begin{array}{l}19.25 \\
(4.04)\end{array}$ & $\begin{array}{l}18.49 \\
(2.63)\end{array}$ & $\begin{array}{l}-0.76 \\
(2.41)\end{array}$ & $\begin{array}{l}21.10 \\
(2.56)\end{array}$ & $\begin{array}{l}1.84 \\
(2.56)\end{array}$ & $\begin{array}{l}20.20 \\
(2.69)\end{array}$ & $\begin{array}{l}0.94 \\
(2.80)\end{array}$ \\
\hline No Touch & $\begin{array}{l}18.94 \\
(3.50)\end{array}$ & $\begin{array}{l}18.49 \\
(3.48)\end{array}$ & $\begin{array}{l}-0.45 \\
(3.32)\end{array}$ & $\begin{array}{l}20.90 \\
(3.78)\end{array}$ & $\begin{array}{l}1.96 \\
(3.38)\end{array}$ & $\begin{array}{l}20.47 \\
(3.37)\end{array}$ & $\begin{array}{l}1.54 \\
(2.82)\end{array}$ \\
\hline & & \multicolumn{2}{|c|}{ Touch } & No touch & $F_{(1,61)}$ & $p$ & Partial $\eta^{2}$ \\
\hline \multicolumn{2}{|l|}{ Affective trust } & \multicolumn{2}{|c|}{$4.80(1.18)$} & $4.42(1.14)$ & 1.52 & .222 & .024 \\
\hline \multicolumn{2}{|l|}{ Perceived trust } & \multicolumn{2}{|c|}{$4.26(0.96)$} & $4.11(0.96)$ & 0.39 & .552 & .006 \\
\hline \multicolumn{2}{|l|}{ Help } & \multicolumn{2}{|c|}{$3.85(1.73)$} & $3.38(1.51)$ & 1.28 & .262 & .021 \\
\hline \multicolumn{2}{|l|}{ Intimacy } & \multicolumn{2}{|c|}{$4.47(1.15)$} & $3.84(1.17)$ & 4.33 & $.042 *$ & .066 \\
\hline \multicolumn{2}{|c|}{ Emotional security } & \multicolumn{2}{|c|}{$3.88(1.66)$} & $3.50(1.19)$ & 0.93 & .339 & .015 \\
\hline \multicolumn{2}{|c|}{ Stimulating companionship } & \multicolumn{2}{|c|}{$3.53(1.70)$} & $3.86(1.85)$ & 0.64 & .425 & .010 \\
\hline
\end{tabular}

Bold-faced, *-marked values indicate significance and Measurement Moment (Pre-Movie, Post-Movie; within subjects) was carried out to further explore the measures intended for the bonding manipulation. The outcomes are listed in Table 5.

Whereas the scores regarding Robot Appearance were not significantly affected by Touching and Bonding, the Attitude towards the Robot MANOVA yielded a significant main effect of Bonding, which was apparent on all three subscales (all $p$ s <.023). Over the course of the experiment, the negative attitude towards robots increased for participants in the No Bond groups, whereas it slightly decreased for participants that formed a Bond with the robot. Bonding also led to differences in impressions of the robot's touching behavior. The individual ANOVAs demonstrated a significant effect on how startling the touch was perceived; people with a Bond $(M$
$=3.47, S D=1.92)$ were more startled by the robot's touching behavior than participants in the No Bond groups $(M=1.56$, $S D=0.51): F_{(1,31)}=16.49, p<.001$, partial $\eta^{2}=.347$.

According to the main effect of Measurement Moment of the $2 \times 2 \times 2$ mixed-model MANOVA, as depicted in Table 5, the perceived relationship with the robot was affected during the movie viewing (Phase 2). Inspection of the individual repeated measures ANOVAs indicated that the strength of the relation generally decreased, and that this effect was mainly applicable for the Anthropomorphism scores: $F_{(1,61)}$ $=10.31, p=.002$, partial $\eta^{2}=.145$. Moreover, there was a significant interaction effect between Measuring Moment and Bonding, which showed that the perceived bond with the robot increased for people in the No Bond groups, but decreased for people that already established a Bond. This 
Table 5 Overview of the exploratory MANOVAs
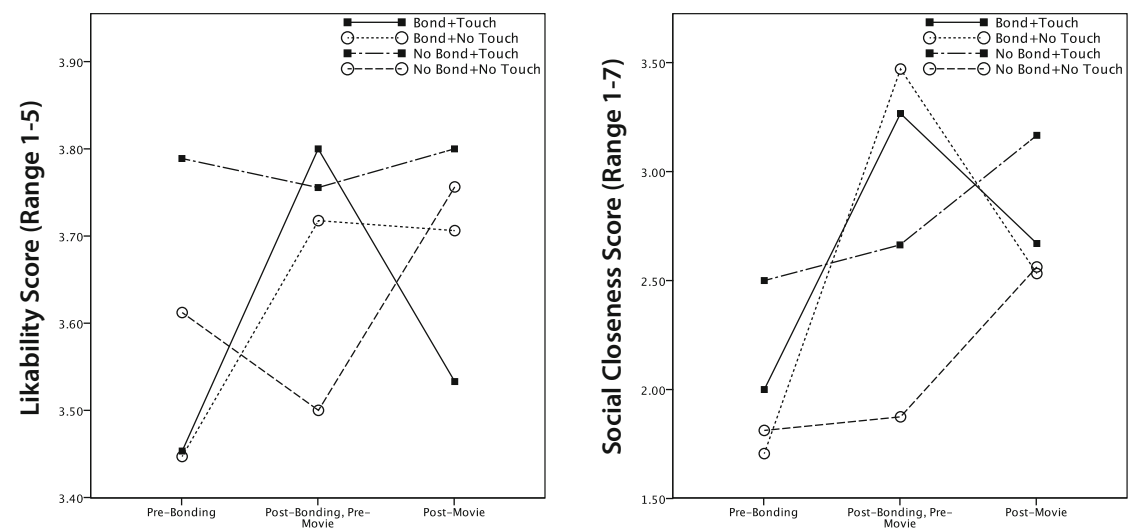

$\begin{array}{lllll}\text { Wilks' } & \text { df } & F & p & \begin{array}{l}\text { Partial } \\ \eta^{2}\end{array}\end{array}$

Robot appearance $(n=65)$ : immediacy, safety, qualification, dynamism

$\begin{array}{llllll}\text { Main effect touch } & .877 & (4,58) & 2.04 & .101 & .123 \\ \text { Main effect bonding } & .935 & (4,58) & 1.01 & .412 & .065 \\ \text { Interaction touching } \times \text { bonding } & .986 & (4,58) & 0.20 & .937 & .014\end{array}$

Attitude towards the robot $(n=65)$ : negative attitude towards (1) interaction with, (2) social influence of, and (3) emotional interactions with robots

$\begin{array}{llllll}\text { Main effect touching } & .904 & (3,59) & 2.08 & .113 & .096 \\ \text { Main effect bonding } & .805 & (3,59) & 4.76 & \mathbf{. 0 0 5} * & .195 \\ \text { Interaction touching } \times \text { bonding } & .995 & (3,59) & 0.10 & .960 & .005\end{array}$

Touch appropriateness $(n=33)$ : calming intentions, calming, appropriate, startling, humanlike
Main effect bonding
.602
$(5,27) \quad 3.57$
$\mathbf{0 . 1 3} * \quad .398$

Perceived bond with the robot $(n=65)$ : social closeness (square root transformed), likability, anthropomorphism, attachment

$\begin{array}{llllll}\text { Main effect touching } & .950 & (4,58) & 0.77 & .552 & .050 \\ \text { Main effect bonding } & .882 & (4,58) & 1.95 & .115 & .118 \\ \text { Interaction touching } \times \text { bonding } & .968 & (4,58) & 0.48 & .748 & .032 \\ \text { Main effect measurement moment }(\mathrm{MM}) & .800 & (4,58) & 3.62 & \mathbf{. 0 1 1} * & .200 \\ \text { Interaction MM } \times \text { touching } & .938 & (4,58) & 0.96 & .438 & .062 \\ \text { Interaction MM } \times \text { bonding } & .572 & (4,58) & 10.86 & <.001 * & .428 \\ \text { Interaction MM } \times \text { touching } \times \text { bonding } & .965 & (4,58) & 0.53 & .713 & \mathbf{. 0 3 5}\end{array}$

$\Delta$-values indicate differences between post-movie and pre-movie scores. Bold-faced, $*$-marked values indicate significant effects

Fig. 5 Progress of the bonding measures over the course of the study

interaction was significant for all dependent variables (Social Closeness and Attachment: $p$ s $<.001$, Likability: $p=.046$ ), except Anthropomorphism $(p=.542)$. The progress of the perceived relationship with the robot over the course of the entire experiment is depicted in Fig. 5.

\subsubsection{Alternative Bonding}

Although the bonding manipulation resulted, at group level, in a stronger bond with the robot in the Bond groups, there

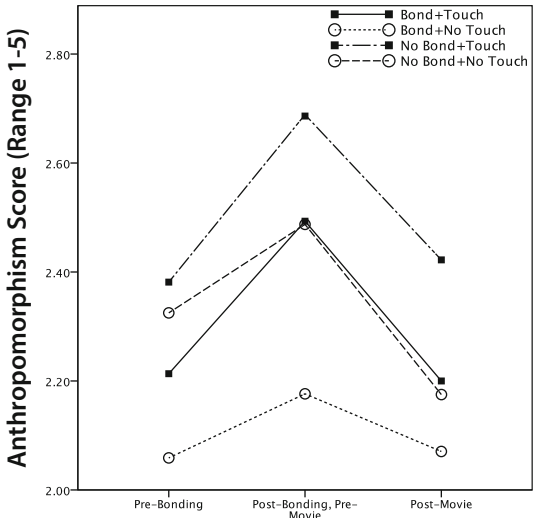

were large individual differences in the questionnaire scores. To gain better insights in to what extent one's actual perceived social relationship with a robot, rather than the a priori defined experimental group, determines the responses to a touch, we computed each participant's Bonding Score. This score (range $=0-6$ ) consisted of the sum of the normalized scores (i.e., converted to values between 0 and 1) of the Likability, Anthropomorphism, and Social Closeness post- and pre-bonding differences, and the Social Presence, Attachment, and Reciprocal Self-Disclosure scales. Whereas 


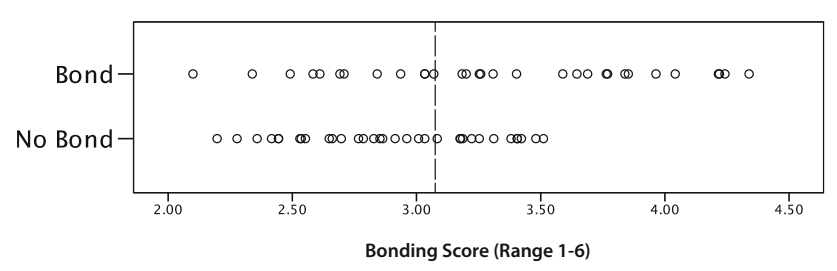

Fig. 6 Scatterplot of the bonding scores per original bonding group. The dashed line indicates the median

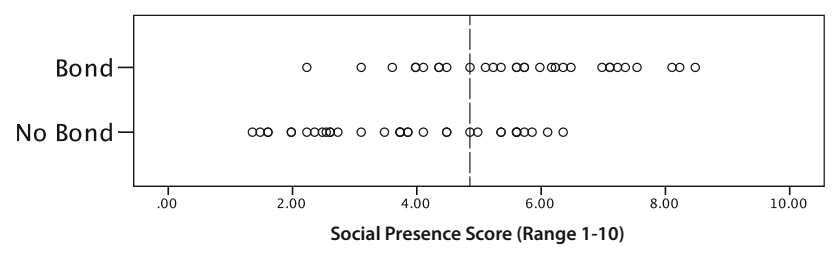

Fig. 7 Scatterplot of the social presence per original bonding group. The dashed line indicates the median

the Bonding Scores for participants in the original No Bond groups were at the lower end of the range $(M=2.91, S D$ $=0.38$ ), the scores for people in the Bond groups were dispersed over a much broader range $(M=3.33, S D=0.61)$. This implies that the perceived bond with the robot not necessarily corresponds with the experimental group (see also the scatterplot in Fig. 6). Therefore, we repeated all analyses, where the original independent variable Bonding was replaced by Perceived Bonding; Low or High new Bonding Scores, dichotomized based on a median split $(M d n=3.07)$.

Moreover, since the perceived Social Presence determines to what extent the robot is perceived as an actual social actor, and modulates the user's social responses to the robot $[72,83,84]$, we carried out additional analyses with Social Presence as substitution for the original IV Bonding. The new IV Social Presence comprised the dichotomized Social Presence scores based on a median split $(M d n=4.88)$, with the levels Low and High (see also: Fig. 7).

Besides strong main effects of Perceived Bonding in the relational one-way and mixed-model MANOVAs, which were to be expected, the analyses did not yield substantially different, or additional insights in the effects of robot-initiated touch and/or in possible interactions between Touching and Perceived Bonding with the robot. The same pattern emerged for Social Presence. The effects are therefore not further reported.

\section{Discussion}

We designed and carried out an experiment to test the hypotheses that robot-initiated touches during stressful circumstances beneficially affect one's emotional state (H1a), one's perceived relation with the robot (H1b), and one's prosocial behavior (H1c). Our results support H1a and H1b: the combination of dependent variables as analyzed with the respective MANOVAs led to significant beneficial effects of touch. These effects were mainly reflected in an attenuation of the increase in heart rate (H1a) and an enhanced feeling of intimacy in the bond with the robot (H1b). No support for H1c was found, as robot-initiated touches did not lead to increased pro-social behavior. Moreover, we hypothesized (H2) that having a bond with the robot prior to the touch interactions would enhance the effects of touch in H1a and H1b. However, no interaction effects between having a bond with the robot and being touched by the robot were found for any of the measures. This also applied when the individual impressions of one's bond with the robot were considered, rather than the original experimental condition. This leads us to reject H2. Here we discuss the findings and reflect on our methodology; firstly with regard to the robot's touch behavior, followed by the role of bonding. Based on the discussions, we provide suggestions for future work.

\subsection{Robot-Initiated Touch}

In line with the effects reported for human touch (e.g., $[33,34,46])$, robotic touches did have beneficial effects on the emotional state of the participants. The physiological stress responses-mainly reflected in the heart rate-during the interaction moments, as well as during the intervals between these interactions, decreased due to the touches. Moreover, robotic touches led to a stronger perceived relation with the robot (mainly reflected in intimacy) during the movie viewing than interactions without physical contact (which also corresponds with findings for human touch $[3,40,51])$. Our findings imply, in line with previous suggestions [130,131], that robotic touches can have similar outcomes as human touches, and that social touch thus can be a valuable extension of the robot's nonverbal communication repertoire. The findings also to some extent contradict the suggestion that affective touches do not lead to positive responses [19] and earlier research that solely comprised of the scary movie interaction [135]. The positive effects of touch should however be interpreted with care. Although MANOVAs have a greater power to detect effects due to the combination of variables investigated [38, p. 586], and although the observed effect sizes (i.e., the partial $\eta^{2}$ 's) can be considered substantial, touching did not significantly affect all associated dependent variables according to the respective individual ANOVAs. Since people tend to expect less social skills from a robot than they do from another human [120], it may be the case that the effects of robot-initiated touch are also less outspoken than those of human touches. If this indeed is the case, a larger sample size would be necessary to detect such potentially small [22] effects. In addition, no effects on pro-social behavior could be observed, which is not in line with earlier robotic Midas Touch research [42,95,118]. A possible expla- 
nation for this discrepancy could be that the effectiveness of the Midas Touch depends on how substantial the request is $[48,136]$. Whereas carrying out a monotonous task $[95,118]$ or accepting or rejecting a fictitious monetary offer [42] may have been relatively trivial, a request for actual money from the participant's own assets may have been a bridge too far. With regard to our exploratory measures, no effects of robotinitiated touches were found on the perceived appearance of the robot and one's attitude towards the robot either. The fact that the touches did not elicit all anticipated physiological, emotional, and behavioral responses can be explained by the physical composition of the touch. This rather mechanical appearance and feel of the touch vastly differs from human touch $[43,57,135]$ and may have felt unpleasant. A robot's touch that feels for example softer and warmer may elicit more outspoken responses. Moreover, the type of touch could severely influence the responses; stroking touches are for example known to be closely correlated with pleasantness perceptions (e.g., [36]).

\subsection{Bonding and Robot-Initiated Touch}

The fact that the effects of touch have been found regardless of the bond with the robot is partially in line with [21], who found that human social touches from both a stranger and a loved one can have stress-attenuating effects. The responses as described by Coan et al. were however stronger when the touches were applied by the partner. The fact that no such modulating effect of relationship was observed in our study may be explained by the relatively small differences between the Bond and the No Bond groups with regard to the perceived strength of the bond with the robot. Although a significantly stronger bond was established for people in the Bond groups, the relatively low scores and substantial variance on the various relational measures suggest that the bonding manipulation only led to a rudimentary relationship (for instance a sense of rapport and acquaintance, as was achieved in earlier research $[66,87,96,104])$. This suggestion is further supported by the fact that an alternative distribution-i.e., based on the participant's individual Bonding Scores-over the experimental groups, did not lead to different results. A social relationship is a persistent construct that is incrementally built and maintained over a series of interactions [12]. The relatively short bonding interaction in our study may simply not have led to a human-robot relationship that is constructive, intimate $[8,30]$, trustworthy, or empathetic [12] enough to be able to elicit more comprehensive and compelling responses to touches than the responses we observed [21,23,59,122].

As mentioned, the observed beneficial effects of robotinitiated touch contradict the findings from earlier work with the same movie viewing paradigm and robot [135]. A possible explanation for the discrepancy between the current effects and the earlier null-effects could be that all participants in the current study already became acquainted with the robot's appearance and physical capabilities prior to the movie interaction. This thus also applied for participants in the No Bond groups, where the robot displayed random idle behavior. This minimal level of familiarity with the robot's capabilities-which is not the same as having a social bondmay have been sufficient for the robotic touches to elicit the anticipated responses. In other words: merely spending time in close vicinity of the robot, and getting acquainted with its capabilities to move, could already be sufficient to elicit responses to robot-initiated social touches that are similar to responses to human touch.

Unexpectedly, people who bonded with the robot perceived its touches as less appropriate than people who did not bond. A possible explanation could be that the touches were unanticipated for people in the Bond groups, as they familiarized with a robot that spoke and displayed nonverbal immediacy behaviors such as movements [12,31], but did not yet touch. Moreover, it could be that the bonding interaction in phase 1 increased the bonders' expectations with regard to the interaction capabilities of the robot $[29,86,89]$. A mismatch may have occurred between these expectations and the rather mechanical appearance and feel of the robot's touch, which vastly differs from human touch $[43,57,135]$. Although other robotic social cues also differ from their human counterparts in terms of abstraction $[14,15]$, the touch discrepancy may have been inadmissible, and detrimental for the social presence illusion [84]. This mismatch may not have occurred for the non-bonders, as their expectations with regard to the robot's interaction capabilities were already low, or simply non-existing. The suggestion that different expectation levels may have affected the results is further substantiated by the exploratory relational measures in the movie phase, which increased for the non-bonders, but decreased for the bonders (see also Fig. 5). For the non-bonders, this can be explained by the fact that the movie interactions were their first actual social interactions with the robot. For the people that bonded with the robot, the decrease in bonding could be explained by the fact that each participant received the same, supposedly comforting, utterances from the robot, regardless of how (s)he actually felt during the movie. These scripted interactions contrast with the robot's seemingly responsive behavior during the bonding phase, and may have made the robot acting less empathetic than expected. The overall decrease of the robot's perceived anthropomorphism during the movie phase also suggests that the scripted interaction may have been detrimental to the interaction. Personalization and adaptation to the user are essential for successful HRI $[14,126]$, or as Dautenhahn puts it: "rather than relying on an inbuilt fixed repertoire of social behaviors, a robot should be able to learn and adapt to the social manners, 
routines, and personal preferences of the people it is living with" [28, p. 17].

\subsection{Future Work}

In the work as presented here, the bonding manipulation did not amplify the responses to robot-initiated touches. However, as discussed, a more constructive and persistent bond with the robot may elicit more pronounced responses to touch. This could be achieved with an experimental approach in which a dyadic relationship between human and robot is built incrementally over multiple sessions $[8,12,30]$, prior to a touch interaction. Moreover, a longitudinal experimental approach, perhaps in a specific context of use, in which the robot—or its operator-applies touches throughout the course of the interaction can be valuable as well. In this approach, the robot can observe the user's response to the touches, learn from it, and adjust its touching behavior accordingly. Contrary to the former suggestion for future work, in which a strong relationship is established prior to a touch interaction, the latter approach adheres more closely to human touching behavior, which also develops over the course of a relationship [23,122,125]. Both approaches can provide substantial additional insights in the possible interplay between bonding and responses to touch.

The social relationship with a robot is-likely—not the only dimension that may affect the effectiveness of robotinitiated touches. Physical HRI comprises a multidimensional challenge [25,135], in which, as discussed, the robot's appearance and social capabilities, as well as the associated expectations, play a role $[29,86,89]$. The interplay between these aspects, and for example also the physical properties of a touch [98], the perceived intentions of a touching robot [19], and other social cues $[14,37,128]$, is hardly understood yet. In addition, the setting in which a robot-initiated touch takes place, as well as personality traits of the human recipient may substantially modulate the perceptions of a touch. To advance this understanding, controlled comparative lab-studies, like the study as presented here, in which a specific 'social touch building block' [131] is investigated, can be valuable. We do however not intend to imply that our methodology is the only way to go; on the contrary. Responses to robot-initiated touches could (and should) be investigated with different paradigms, methodologies, and measures. For example, although challenging, field-studies with video observations could provide more ecologically valid insights. Recent endeavors also suggest that online crowdsourcing studies with pictures or videos could be a viable and convenient addition to the methodologies as well (e.g., $[111,134])$. Only with many different studiesand replications thereof, for that matter-we can develop a coherent body of knowledge regarding the responses to robot-initiated touch and the boundary conditions within which such touch can elicit effects. This is because, as Hertenstein describes: "Tactile communication occurs when the various qualities and parameters of contact are orchestrated together, thereby resulting in a 'tactile gestalt' " [57, p. 82].

\section{Conclusions}

A social touch that is provided by a robot can attenuate physiological stress responses (in particular the heart rate) and increase the sense of intimacy between the human and robot, regardless of whether a social bond is established or not. That is to say, a (rudimentary) sense of rapport and acquaintance with the robot, as was established in our study, does not amplify physiological, emotional, and behavioral responses to touches from a robot as compared to simply spending time in the robot's vicinity without interacting with it. No support was found for the hypothesis that a social bond modulates responses to touches provided by a robot in a similar way as in human-human interaction. The results imply that mere familiarity with the robot's appearance and movements already suffices in eliciting beneficial responses to robot-initiated touches, although this does not apply for all anticipated responses. Future research should investigate the possible influence of more advanced human-robot bonding, as well as the influence of additional 'social touch building blocks', the setting, and the recipient's personality on the various responses to robot-initiated touch. A thorough understanding of the boundary conditions for effective robotinitiated touch is necessary to apply this communication modality successfully; in particular with regard to robots' envisioned role as supportive companions. In this regard, our results are promising as they indeed suggest that touch may become a valuable extension of a social robot's nonverbal communication repertoire.

Acknowledgements We would like to thank our intern Vera van der Hout for her help in preparing the experiment and for leading the experimental sessions.

Open Access This article is distributed under the terms of the Creative Commons Attribution 4.0 International License (http://creativecomm ons.org/licenses/by/4.0/), which permits unrestricted use, distribution, and reproduction in any medium, provided you give appropriate credit to the original author(s) and the source, provide a link to the Creative Commons license, and indicate if changes were made.

\section{References}

1. Andersen JF, Andersen PA, Jensen AD (1979) The measurement of nonverbal immediacy. J Appl Commun Res 7(2):153-180. https://doi.org/10.1080/00909887909365204

2. Anderson N, Glickert R (2006) The descendent. Chapman University film school, USA 
3. App B, McIntosh DN, Reed CL, Hertenstein MJ (2011) Nonverbal channel use in communication of emotion: how may depend on why. Emotion 11(3):603-617. https://doi.org/10.1037/a0023164

4. Argyle M (1988) Bodily communication, 2nd edn. Routledge, London

5. Aron A, Aron EN, Tudor M, Nelson G (1991) Close relationships as including other in the self. J Pers Soc Psychol 60(2):241-253. https://doi.org/10.1037//0022-3514.60.2.241

6. Bailenson JN, Yee N, Brave S, Merget D, Koslow D (2007) Virtual interpersonal touch: expressing and recognizing emotions through haptic devices. Hum Comput Interact 22:325-353. https://doi.org/ 10.1080/07370020701493509

7. Bartneck C, Kulić D, Croft E, Zoghbi S (2009) Measurement Instruments for the anthropomorphism, animacy, likeability, perceived intelligence, and perceived safety of robots. Int J Soc Robot 1(1):71-81. https://doi.org/10.1007/s12369-008-0001-3

8. Baxter P, Belpaeme T, Cañamero L, Enescu V, Brussel V.U March (2011) Long-term human-robot interaction with young users. In: 2011 6th ACM/ieee international conference on human-robot interaction (HRI). https://doi.org/10.1111/1467-8721.01225

9. Bellieni CV, Cordelli DM, Marchi S, Ceccarelli S, Perrone S, Maffei M, Buonocore G (2007) Sensorial saturation for neonatal analgesia. Clin J Pain 23(3):219-221. https://doi.org/10.1097/ AJP.0b013e31802e3bd7

10. Berlo DK, Lemert JB, Mertz RJ (1969) Dimensions for evaluating the acceptability of message sources. Public Opin Q 33(4):563576

11. Bickmore T, Cassell J (1999) Small talk and conversational storytelling in embodied conversational interface agents. In: Proceedings of AAAI fall symposium on narrative intelligence, $\mathrm{pp}$ 87-92

12. Bickmore TW, Picard RW (2005) Establishing and maintaining long-term human-computer relationships. ACM Trans Comput Interact 12(2):293-327

13. Bradley MM, Lang PJ (1994) Measuring emotion: the selfassessment manikin and the semantic differential. J Behav Ther Exp Psychiatry 25(1):49-59

14. Breazeal C (2003) Toward sociable robots. Robot Auton Syst 42(3-4):167-175. https://doi.org/10.1016/S09218890(02)00373-1

15. Breazeal C (2004) Social interactions in HRI: the robot view. IEEE Trans Syst Man Cybern Part C Appl Rev 34(2):181-186. https://doi.org/10.1109/TSMCC.2004.826268

16. Breazeal C (2011) Social robots for health applications. In: annual international conference of the IEEE engineering in medicine and biology society, pp 5368-5371. https://doi.org/10.1109/IEMBS. 2011.6091328

17. Brown P, Levinson SC (1978) Universals in language usage: politeness phenomena. In: Goody E (ed) Questions and politeness strategies in social interaction. Cambridge University Press, Cambridge, pp 56-311

18. Cabibihan JJ, Chauhan S (2017) Physiological responses to affective tele-touch during induced emotional stimuli. IEEE Trans Affect Comput 8(1):108-118. https://doi.org/10.1109/TAFFC. 2015.2509985

19. Chen TL, King CHA, Thomaz AL, Kemp CC (2014) An investigation of responses to robot-initiated touch in a nursing context. Int J Soc Robot 6(1):141-161. https://doi.org/10.1007/s12369013-0215-x

20. Clark MS, Reis HT (1988) Interpersonal processes in close relationships. Annu Rev Psychol 39:609-672

21. Coan JA, Schaefer HS, Davidson RJ (2006) Lending a hand: social regulation of the neural response to threat. Psychol Sci 17(12):1032-1039. https://doi.org/10.1111/j.14679280.2006.01832.x

22. Cohen J (1992) A power primer. Psychol Bull 112(1):155-159
23. Collier G (1985) Emotional expression. Lawrence Erlbaum Associates, Hillsdale

24. Collins NL, Miller LC (1994) Self-disclosure and liking: a metaanalytic review. Psychol Bull 116(3):457-475

25. Cramer H, Kemper NA, Amin A, Wielinga B, Evers V (2009) Give me a hug: the effects of touch and autonomy on people's responses to embodied social agents. Comput Animat Virtual Worlds 20(June):437-445. https://doi.org/10.1002/cav

26. Cranny-Francis A (2011) Social semiotics semefulness: a social semiotics of touch. Soc Semiot 21(4):463-481

27. Crusco AH, Wetzel CG (1984) The midas touch: the effects of interpersonal touch on restaurant tipping. Personal Soc Psychol Bull 10(4):512-517. https://doi.org/10.1177/0146167284104003

28. Dautenhahn K (2004) Robots we like to live with?! - a developmental perspective on a personalized, life-long robot companion. In: 13th IEEE international workshop on robot and human interactive communication. RO-MAN 2004. (IEEE Cat. No.04TH8759), pp. 17-22 . https://doi.org/10.1109/ROMAN.2004.1374720

29. Dautenhahn K (2007) Socially intelligent robots: dimensions of human-robot interaction. Philos Trans R Soc Lond B Biol Sci 362(1480):679-704. https://doi.org/10.1098/rstb.2006.2004

30. De Graaf MMA, Allouch SB, Klamer T (2015) Sharing a life with Harvey: exploring the acceptance of and relationship-building with a social robot. Comput Human Behav 43:1-14. https://doi. org/10.1016/j.chb.2014.10.030

31. De Ruyter B, Saini P, Markopoulos P, Van Breemen A (2005) Assessing the effects of building social intelligence in a robotic interface for the home. Interact Comput 17(5):522-541. https:// doi.org/10.1016/j.intcom.2005.03.003

32. Dillard JP, Solomon DH, Palmer MT (1999) Structuring the concept of relational communication. Commun Monogr 66(1):49-65. https://doi.org/10.1080/03637759909376462

33. Ditzen B, Neumann ID, Bodenmann G, von Dawans B, Turner RA, Ehlert U, Heinrichs M (2007) Effects of different kinds of couple interaction on cortisol and heart rate responses to stress in women. Psychoneuroendocrinology 32(5):565-574. https://doi. org/10.1016/j.psyneuen.2007.03.011

34. Dolin DJ, Booth-Butterfield M (1993) Reach out and touch someone: analysis of nonverbal comforting responses. Commun Q 41(4):383-393. https://doi.org/10.1080/01463379309369899

35. Erdfelder E, Faul F, Buchner A (1996) GPOWER: a general power analysis program. Behav Res Methods Instrum Comput 28(1):111

36. Essick GK, McGlone F, Dancer C, Fabricant D, Ragin Y, Phillips N, Jones T, Guest S (2010) Quantitative assessment of pleasant touch. Neurosci Biobehav Rev 34(2):192-203. https://doi.org/10. 1016/j.neubiorev.2009.02.003

37. Eyssel F, Kuchenbrandt D, Hegel F, De Ruiter L (2012) Activating elicited agent knowledge: how robot and user features shape the perception of social robots. In: IEEE RO-MAN 21st IEEE international symposium on robot and human interactive communication, pp 851-857. Paris https://doi.org/10.1109/ROMAN. 2012.6343858

38. Field AP (2009) Discovering statistics using IBM SPSS statistics, vol 58, 3rd edn. Sage, Thousand Oaks

39. Field T (2001) Touch. MIT Press, Cambridge

40. Field $\mathrm{T}$ (2010) Touch for socioemotional and physical well-being: a review. Dev Rev 30(4):367-383. https://doi.org/10.1016/j.dr. 2011.01.001

41. Fong T, Thorpe C, Baur C (2001) Collaboration, dialogue, and human-robot interaction. In: Proceedings of the 10th international symposium of robotics research, November, pp 255-266. https:// doi.org/10.1055/s-0031-1280784

42. Fukuda H, Shiomi M, Nakagawa K, Ueda K (2012) 'Midas touch' in human-robot interaction: evidence from event-related potentials during the ultimatum game. In: Proceedings of the 
seventh annual ACM/IEEE international conference on humanrobot interaction. Boston, pp 131-132. https://doi.org/10.1145/ 2157689.2157720

43. Gallace A, Spence C (2010) The science of interpersonal touch: an overview. Neurosci Biobehav Rev 34(2):246-259. https://doi. org/10.1016/j.neubiorev.2008.10.004

44. Gockley R, Bruce A, Forlizzi J, Michalowski M, Mundell A, Rosenthal S, Sellner B, Simmons R, Snipes K, Schultz AC, Wang J, Dc W (2005) Designing robots for long-term social interaction, pp 2199-2204

45. Gonsior B, Sosnowski S, Buß M, Wollherr D, Kühnlenz K (2012) An emotional adaption approach to increase helpfulness towards a robot. In: IEEE/RSJ international conference on intelligent robots and systems. Vilamoura, pp 2429-2436. https://doi.org/10.1109/ IROS.2012.6385941

46. Grewen KM, Anderson BJ, Girdler SS, Light KC (2003) Warm partner contact is related to lower cardiovascular reactivity. Behav Med 29(3):123-130. https://doi.org/10.1080/ 08964280309596065

47. Guéguen N (2002) Touch, awareness of touch, and compliance with a request. Percept Mot Skills 95:355-360

48. Guéguen N, Afifi F, Brault S, Charles-Sire V, Leforestier PM, Morzedec A, Piron E (2011) Failure of tactile contact to increase request compliance: the case of blood donation behavior. J Artic Support Null Hypothesis 8(1):1-8

49. Guéguen N, Fischer-Lokou J (2003) Tactile contact and spontaneous help: an evaluation in a natural setting. J Soc Psychol 143(6):785-787

50. Guéguen N, Joule RV (2008) Contact tactile et acceptation d'une requete: une Meta-analyse. Les Cah Int Psychol Soc 80:39-58

51. Gulledge AK, Hill M, Lister Z, Sallion C (2007) Non-erotic physical affection: it's good for you. In: L'Abate L (ed) Lowcost approaches to promote physical and mental health: theory, research, and practice. Springer, New York, pp 371-384 (chapter 18)

52. Haans A, de Bruijn R, IJsselsteijn WA (2014) A virtual midas touch? touch, compliance, and confederate bias in mediated communication. J Nonverbal Behav 38(3):301-311

53. Haans A, IJsselsteijn WA (2006) Mediated social touch: a review of current research and future directions. Virtual Real 9:149-159. https://doi.org/10.1007/s10055-005-0014-2

54. Haans A, IJsselsteijn WA (2009) The virtual midas touch: helping behavior after a mediated social touch. IEEE Trans Haptics 2(3): $136-140$

55. Hannan D (2010) Coral sea dreaming: awaken. Plankton Productions, Australia

56. Heinrichs $M$, Baumgartner $T$, Kirschbaum $C$, Ehlert $U$ (2003) Social support and oxytocin interact to suppress cortisol and subjective responses to psychosocial stress. Biol Psychiatry 54(12):1389-1398. https://doi.org/10.1016/S00063223(03)00465-7

57. Hertenstein MJ (2002) Touch: its communicative functions in infancy. Hum Dev 45(2):70-94

58. Hertenstein MJ, Verkamp JM, Kerestes AM, Holmes RM (2006) The communicative functions of touch in humans, nonhuman primates, and rats: a review and synthesis of the empirical research. Genet Soc Gen Psychol Monogr 132(1):5-94

59. Heslin R, Alper T (1983) Touch: a bonding gesture. In: Wiemann JM, Harrison RP (eds) Nonverbal interact. Sage, Beverly Hills, pp 47-75

60. Hieida C, Abe K, Attamimi M, Shimotomai T, Nagai T, Omori $\mathrm{T}$ (2014) Physical embodied communication between robots and children: an approach for relationship building by holding hands. In: IEEE international conference on intelligent robots and systems, IROS, pp 3291-3298. https://doi.org/10.1109/IROS.2014. 6943020
61. Huisman G (2017) Social touch technology: a survey of haptic technology for social touch. IEEE Trans Haptics 10(3):391-408. https://doi.org/10.1109/TOH.2017.2650221

62. Jakobson R (1960) Linguistics and poetics. In: Sebeok TA (ed) Style in language. MIT Press, Cambridge, pp 130-144. https:// doi.org/10.1002/car.1158

63. Johnson D, Grayson K (2005) Cognitive and affective trust in service relationships. J Bus Res 58(4):500-507. https://doi.org/ 10.1016/S0148-2963(03)00140-1

64. Jones SE, Yarbrough AE (1985) A naturalistic study of the meanings of touch. Commun Monogr 52(1):19-52

65. Joule RV, Guéguen N (2007) Touch, compliance, and awareness. Percept Mot Skills 104:581-588

66. Kahn PH, Kanda T, Ishiguro H, Gill BT, Shen S, Gary HE, Ruckert JH (2015) Will people keep the secret of a humanoid robot? In: Proceedings of the tenth annual ACM/IEEE international conference on human-robot interaction-HRI'15, pp 173-180. https:// doi.org/10.1145/2696454.2696486

67. Kanda T, Hirano T, Eaton D, Ishiguro H (2004) Interactive robots as social partners and peer tutors for children: a field trial. Hum Comput Interact 19(1):61-84

68. Kawamichi H, Kitada R, Yoshihara K, Takahashi HK, Sadato N (2015) Interpersonal touch suppresses visual processing of aversive stimuli. Front Hum Neurosci 9:164. https://doi.org/10.3389/ fnhum.2015.00164

69. Kidd CD (2003) Sociable robots: the role of presence and task in human-robot interaction. Ph.D. thesis

70. Kidd C.D, Breazeal C (2008) Robots at home: Understanding long-term human-robot interaction. 2008 IEEE/RSJ international conference on intelligent robots and systems, IROS, pp 3230 3235. https://doi.org/10.1109/IROS.2008.4651113

71. Kidwell M, Zimmerman DH (2007) Joint attention as action. J Pragmat 39(3):592-611. https://doi.org/10.1016/j.pragma.2006. 07.012

72. Kim KJ, Park E, Sundar SS (2013) Caregiving role in humanrobot interaction: a study of the mediating effects of perceived benefit and social presence. Comput Hum Behav 29(4):1799_ 1806. https://doi.org/10.1016/j.chb.2013.02.009

73. Kim KJ, Park E, Sundar SS, del Pobil AP (2012) The effects of immersive tendency and need to belong on human-robot interaction. In: Proceedings of the seventh annual ACM/IEEE international conference on human-robot interaction-HRI' 12, pp 207-208. https://doi.org/10.1145/2157689.2157758

74. Kozima H, Nakagawa C, Yano H (2004) Can a robot empathize with people? Artif Life Robot 8(1):83-88. https://doi.org/10. 1007/s10015-004-0293-9

75. Krämer NC, von der Pütten A, Eimler S (2012) Human-agent and human-robot interaction theory: similarities to and differences from human-human interaction. In: Zacarias M, de Oliveira JV (eds) Human-computer interaction: the agency perspective, vol 396. no 9. Springer, Berlin, pp 215-240

76. Krämer NC, Rosenthal-von der Pütten AM, Hoffmann L (2015) Social effects of virtual and robot companions. In: Shyam Sundar $\mathrm{S}$ (ed) The handbook of the psychology of communication technology. Wiley, New York, pp 137-159. https://doi.org/10.1002/ 9781118426456.ch6 (chapter 6)

77. Krebs DL (1970) Altruism: an examination of the concept and a review of the literature. Psychol Bull 73(4):258-302. https://doi. org/10.1037/h0028987

78. Kreibig SD (2010) Autonomic nervous system activity in emotion: a review. Biol Psychol 84(3):394-421. https://doi.org/10. 1016/j.biopsycho.2010.03.010

79. Kruijff-Korbayová I, Elettra O, Bagherzadhalimi A, Sacchitelli F, Bernd K, Stefania R, Pozzi C, Sanna A (2015) Young users' perception of a social robot displaying familiarity and eliciting 
disclosure. In: International conference on social robotics, pp 380-389. https://doi.org/10.1007/978-3-319-255554-5

80. Lang PJ (1995) The emotion probe: studies of motivation and attention. Am Psychol 50(5):372-385

81. Laurenceau JP, Barrett LF, Pietromonaco PR (1998) Intimacy as an interpersonal process: the importance of self-disclosure, partner disclosure, and perceived partner responsiveness in interpersonal exchanges. J Pers Soc Psychol 74(5):1238-1251. https:// doi.org/10.1037//0022-3514.74.5.1238

82. Laver JDMH (1981) Linguistic routines and politeness in greeting and parting. In: Coulmas F (ed) Conversational routine: explorations in standardized communication situations and prepatterned speech. Mouton, The Hague, pp 289-304

83. Lee KM (2004) Presence, explicated. Commun Theory 14(1):2750. https://doi.org/10.1093/ct/14.1.27

84. Lee KM, Jung Y, Kim J, Kim SR (2006) Are physically embodied social agents better than disembodied social agents?: the effects of physical embodiment, tactile interaction, and people's loneliness in human-robot interaction. Int J Hum Comput Stud 64(10):962973. https://doi.org/10.1016/j.ijhcs.2006.05.002

85. Lee KM, Nass C (2003) Designing social presence of social actors in human computer interaction. Proc CHI 2003(1):289-296

86. Leite I, Martinho C, Paiva A (2013) Social robots for long-term interaction: a survey. Int J Soc Robot 5(2):291-308. https://doi. org/10.1007/s12369-013-0178-y

87. Leite I, Pereira A, Mascarenhas S, Martinho C, Prada R, Paiva A (2013) The influence of empathy in human-robot relations. Int J Hum Comput Stud 71(3):250-260

88. Levinson SC (1983) Pragmatics. Cambridge University Press, Cambridge

89. Lohse M (2011) Bridging the gap between users' expectations and system evaluations. In: Proceedings of the international workshop on robot and human interactive communication, pp 485-490. https://doi.org/10.1109/ROMAN.2011.6005252

90. Lykken DT, Venables PH (1971) Direct measurement of skin conductance: a proposal for standardization. Psychophysiology $8(5): 656-672$

91. Mandryk RL, Inkpen KM, Calvert TW (2006) Using psychophysiological techniques to measure user experience with entertainment technologies. Behav Inf Technol 25(2):141-158. https://doi. org/10.1080/01449290500331156

92. Master SL, Eisenberger NI, Taylor SE, Naliboff BD, Shirinyan D, Lieberman MD (2009) A picture's worth: partner photographs reduce experimentally induced pain. Psychol Sci 20(11):13161318. https://doi.org/10.1111/j.1467-9280.2009.02444.x

93. Montagu A (1972) Touching: the human significance of the skin. Harper \& Row Publishers, New York, USA

94. Moon Y (2000) Intimate exchanges: using computers to elicit self-disclosure from consumers. J Consum Res 26(4):323-339. https://doi.org/10.1086/209566

95. Nakagawa K, Shiomi M, Shinozawa K, Matsumura R, Ishiguro H, Hagita N (2011) Effect of robot's active touch on people's motivation. In: Proceedings of the 6th international conference on human-robot interaction-HRI'11. ACM Press, New York, pp 465-472. https://doi.org/10.1145/1957656.1957819

96. Nass C, Fogg B, Moon Y (1996) Can computers be teammates? Int J Hum Comput Stud 45(6):669-678. https://doi.org/10.1006/ ijhc. 1996.0073

97. Nass C, Moon Y, Fogg BJ, Reeves B, Dryer DC (1995) Can computer personalities be human personalities? Int J Hum Comput Stud 43:223-239

98. Nie J, Park M, Marin AL, Shyam Sundar S (2012) Can you hold my hand? physical warmth in human-robot interaction. In: Proceedings of human-robot interaction, pp 201-202. https://doi.org/ $10.1145 / 2157689.2157755$
99. Nomura T, Kanda T, Suzuki T, Kato K (2008) Prediction of human behavior in human-robot interaction using psychological scales for anxiety and negative attitudes toward robots. IEEE Trans Robot 24(2):442-451. https://doi.org/10.1109/TRO.2007. 914004

100. Oostenveld R, Fries P, Maris E, Schoffelen JM (2011) FieldTrip: open source software for advanced analysis of MEG, EEG, and invasive electrophysiological data. Comput Intell Neurosci 2011:1-9. https://doi.org/10.1155/2011/156869

101. Patterson ML, Powell JL, Lenihan MG (1986) Touch, compliance, and interpersonal affect. J Nonverbal Behav 10(1):41-50

102. Pearce WB, Wiebe B (1975) Item-analysis of Jourard's selfdisclosure questionniare-21. Educ Psychol Meas 35:115-118

103. Peeters FPML, Ponds RWHM, Vermeeren MTG (1996) Affectiviteit en zelfbeoordeling van depressie en angst. Tijdschr Psychiatr 38(3):240-250

104. Pereira A, Leite I, Mascarenhas S, Martinho C, Paiva A (2011) Using empathy to improve human-robot relationships. In: Lamers $\mathrm{MH}$, Verbeek FJ (eds) International conference on human-robot personal relationship, Lecture notes of the institute for computer sciences, social informatics and telecommunications engineering, vol 59. Springer, Berlin, pp 130-138

105. Piferi RL, Kline KA, Younger J, Lawler KA (2000) An alternative approach for achieving cardiovascular baseline: viewing an aquatic video. Int J Psychophysiol 37(2):207-217. https://doi.org/ 10.1016/S0167-8760(00)00102-1

106. Reeves B, Nass C (1996) The media equation: how people treat computers, and new media like real people and places. CSLI Publications, Stanford

107. Reis HT, Clark MS, Holmes JG (2004) Perceived partner responsiveness as an organizing construct in the study of intimacy and closeness. In: Mashek DJ, Aron A (eds) Handbook of closeness and intimacy. Lawrence Erlbaum Associates, Mahwah, pp 201225 (chapter 12)

108. Robins B, Dickerson P, Stribling P, Dautenhahn K (2004) Robotmediated joint attention in children with autism: a case study in robot-human interaction. Interact Stud 5(2):161-198. https://doi. org/10.1075/is.5.2.02rob

109. Rooney B, Benson C, Hennessy E (2012) The apparent reality of movies and emotional arousal: a study using physiological and self-report measures. Poetics 40(5):405-422. https://doi.org/10. 1016/j.poetic.2012.07.004

110. Rosenthal S, Biswas J, Veloso M (2010) An effective personal mobile robot agent through symbiotic human-robot interaction. In: Proceedings of the 9th international conference on autonomous agents and multiagent systems (AAMAS 2010), pp 915-922

111. Rosenthal-Von Der Pütten AM, Krämer NC (2014) How design characteristics of robots determine evaluation and uncanny valley related responses. Comput Hum Behav 36:422-439. https://doi. org/10.1016/j.chb.2014.03.066

112. Rubin RB, Rubin AM, Graham EE, Perse EM, Seibold DR (2009) Communication research measures II: a sourcebook. Routledge, New York

113. Sabelli AM, Kanda T, Hagita NA (2011) conversational robot in an elderly care center: An ethnographic study. In: Proceedings of the 6th international conference on human-robot interaction, pp 37-44. https://doi.org/10.1145/1957656.1957669

114. Salter T, Dautenhahn K, Te Boekhorst R (2006) Learning about natural human-robot interaction styles. Robot Auton Syst 54(2):127-134. https://doi.org/10.1016/j.robot.2005.09.022

115. Schifferstein HNJ, Zwartkruis-Pelgrim EPH (2008) Consumerproduct attachment: measurement and design implications. Int $\mathrm{J}$ Des 2(3):1-14

116. Schneider KP (1988) Small talk: analysing phatic discourse. Hitzeroth, Marburg 
117. Severinson-Eklundh K, Green A, Huttenrauch H (2003) Social and colaborative aspects of interaction with a service robot. Robot Auton Syst 42:223-234

118. Shiomi M, Nakagawa K, Shinozawa K, Matsumura R, Ishiguro H, Hagita N (2017) Does a robot's touch encourage human effort? Int J Soc Robot 9(1):5-15. https://doi.org/10.1007/s12369-0160339-x

119. Smith J, MacLean KE (2007) Communicating emotion through a haptic link: design space and methodology. Int J Hum Comput Stud 65(4):376-387. https://doi.org/10.1016/j.ijhcs.2006.11.006

120. Spence PR, Westerman D, Edwards C, Edwards A (2014) Welcoming our robot overlords: initial expectations about interaction with a robot. Commun Res Rep 31(3):272-280

121. Stern RM, Ray WJ, Quigley KS (2001) Psychophysiological recording. Oxford University Press, New York

122. Suvilehto JT, Glerean E, Dunbar RIM, Hari R, Nummenmaa L (2015) Topography of social touching depends on emotional bonds between humans. Proc Natl Acad Sci 112(45):1381113816. https://doi.org/10.1073/pnas.1519231112

123. Tajfel H, Billig MG, Bundy RP, Flament C (1971) Social categorization and intergroup behaviour. Eur J Soc Psychol 1(2):149178. https://doi.org/10.1002/ejsp.2420010202

124. The North American Society of pacing electrophysiology-task force of the European society of cardiology: heart rate variability: standards of measurement, physiological interpretation, and clinical use. Technical report 5 (1996). https://doi.org/10.1161/ 01.CIR.93.5.1043

125. Thompson EH, Hampton JA (2011) The effect of relationship status on communicating emotions through touch. Cogn Emot 25(2):295-306. https://doi.org/10.1080/02699931.2010.492957

126. Torrey C, Powers A, Marge M, Fussell S.R, Kiesler S (2006) Effects of adaptive robot dialogue on information exchange and social relations. In: 1st ACM SIGCHI/SIGART conference on human-robot interaction (HRI '06), pp 126-133. https://doi.org/ $10.1145 / 1121241.1121264$

127. Trounce K, Macé D, Wajsbrot A (2010) Red balloon. Hurricane Productions, France

128. Tsalamlal MY, Martin JC, Ammi M, Tapus A, Amorim MA (2015) Affective handshake with a humanoid robot: how do participants perceive and combine its facial and haptic expressions? In: Proceedings of the 6th conference on affective computing and intelligent interaction, pp 334-340

129. Tsetserukou D, Neviarouskaya A (2010) iFeel_IM!: augmenting emotions during online communication. IEEE Comput Graph Appl 30(5):72-80

130. van Erp J.B.F, Toet A (2013) How to touch humans: guidelines for social agents and robots that can touch. In: International conference on affective computing and intelligent interaction, vol 1, pp 780-785, Geneva. https://doi.org/10.1109/ACII.2013.145

131. van Erp JBF, Toet A (2015) Social touch in human-computer interaction. Front Digit Humanit 2(2):1-14. https://doi.org/10. 3389/fdigh.2015.00002

132. Watson D, Clark LA, Tellegen A (1988) Development and validation of brief measures of positive and negative affect: the PANAS scales. J Pers Soc Psychol 54(6):1063-1070
133. Whitcher SJ, Fisher JD (1979) Multidimensional reaction to therapeutic touch in a hospital setting. J Pers Soc Psychol 37(1):87-96. https://doi.org/10.1037/0022-3514.37.1.87

134. Willemse C.J.A.M, Huisman G, Jung M.M, van Erp J.B.F, Heylen D.K.J (2016) Observing touch from video: the influence of social cues on pleasantness perceptions. In: International conference on human haptic sensing and touch enabled computer applications, pp 196-205. https://doi.org/10.1007/978-3-319-42324-1

135. Willemse CJAM, Toet A, van Erp JBF (2017) Affective and behavioral responses to robot-initiated social touch: towards understanding the opportunities and limitations of physical contact in human-robot interaction. Front ICT 4:12. https://doi.org/ 10.3389/fict.2017.00012

136. Willis FN, Hamm HK (1980) The use of interpersonal touch in securing compliance. J Nonverbal Behav 5(1):49-55. https://doi. org/10.1007/BF00987054

137. World Medical Association (2013) World Medical Association declaration of Helsinki: ethical principles for medical research involving human subjects. J Am Med Assoc 310(20):2191-2194

Publisher's Note Springer Nature remains neutral with regard to jurisdictional claims in published maps and institutional affiliations.

Christian J. A. M. Willemse is a Ph.D. candidate, who has carried out his research with the Human Media Interaction group at the University of Twente and with the Perceptual and Cognitive Systems group of The Netherlands Organization for Applied Scientific Research (TNO), both in the Netherlands. His research evolved around the topic of Social Touch Technology; both focusing on mediated social touch and robot-initiated touch. Christian has obtained his Bachelor degree in Industrial Design and his Master degree in Human-Technology Interaction; both at Eindhoven University of Technology in the Netherlands. He also was a visiting student at the National University of Singapore and at the Royal Institute of Technology (KTH) in Stockholm, Sweden.

Jan B. F. van Erp is principal scientist with The Netherlands Organization for Applied Scientific Research (TNO) and full professor of tangible user interaction with the University of Twente. Jan obtained a Master degree in Experimental Psychology from Leiden University and a Ph.D. in Computer Science from Utrecht University, both in The Netherlands. His research focuses on multisensory perception and cognition, applied neuroscience, robotics, and human-machine collaboration in complex environments. Jan published more than a hundred peer reviewed papers and serves on the editorial board of four scientific journals. Jan is the current vice-president of the Eurohaptics Society, board member of the foundation ICT for Brain, Body and Behaviour, and the general chair of Eurohaptics 2020. 